\title{
The MESSy aerosol submodel MADE3 (v2.0b): description and a box model test
}

\author{
J. C. Kaiser ${ }^{1}$, J. Hendricks ${ }^{1}$, M. Righi ${ }^{1}$, N. Riemer ${ }^{2}$, R. A. Zaveri ${ }^{3}$, S. Metzger ${ }^{4,5}$, and V. Aquila ${ }^{6}$ \\ ${ }^{1}$ Deutsches Zentrum für Luft- und Raumfahrt (DLR), Institut für Physik der Atmosphäre, Oberpfaffenhofen, Germany \\ ${ }^{2}$ Department of Atmospheric Sciences, University of Illinois at Urbana-Champaign, Urbana, IL, USA \\ ${ }^{3}$ Atmospheric Sciences and Global Change Division, Pacific Northwest National Laboratory, Richland, WA 99352, USA \\ ${ }^{4}$ The Cyprus Institute, Nicosia, Cyprus \\ ${ }^{5}$ Max Planck Institute for Chemistry, Mainz, Germany \\ ${ }^{6}$ GESTAR/Johns Hopkins University, Department of Earth and Planetary Sciences, Baltimore, MD, USA
}

Correspondence to: J. C. Kaiser (christopher.kaiser@dlr.de)

Received: 13 December 2013 - Published in Geosci. Model Dev. Discuss.: 21 January 2014

Revised: 16 April 2014 - Accepted: 25 April 2014 - Published: 17 June 2014

\begin{abstract}
We introduce MADE3 (Modal Aerosol Dynamics model for Europe, adapted for global applications, 3rd generation; version: MADE3v2.0b), an aerosol dynamics submodel for application within the MESSy framework (Modular Earth Submodel System). MADE3 builds on the predecessor aerosol submodels MADE and MADE-in. Its main new features are the explicit representation of coarse mode particle interactions both with other particles and with condensable gases, and the inclusion of hydrochloric acid $(\mathrm{HCl})$ / chloride $(\mathrm{Cl})$ partitioning between the gas and condensed phases. The aerosol size distribution is represented in the new submodel as a superposition of nine lognormal modes: one for fully soluble particles, one for insoluble particles, and one for mixed particles in each of three size ranges (Aitken, accumulation, and coarse mode size ranges).

In order to assess the performance of MADE3 we compare it to its predecessor MADE and to the much more detailed particle-resolved aerosol model PartMC-MOSAIC in a box model simulation of an idealised marine boundary layer test case. MADE3 and MADE results are very similar, except in the coarse mode, where the aerosol is dominated by sea spray particles. $\mathrm{Cl}$ is reduced in MADE3 with respect to MADE due to the $\mathrm{HCl} / \mathrm{Cl}$ partitioning that leads to $\mathrm{Cl}$ removal from the sea spray aerosol in our test case. Additionally, the aerosol nitrate concentration is higher in MADE3 due to the condensation of nitric acid on coarse mode particles. MADE3 and PartMC-MOSAIC show substantial differences
\end{abstract}

in the fine particle size distributions (sizes $\lesssim 2 \mu \mathrm{m}$ ) that could be relevant when simulating climate effects on a global scale. Nevertheless, the agreement between MADE3 and PartMC-MOSAIC is very good when it comes to coarse particle size distributions (sizes $\gtrsim 2 \mu \mathrm{m}$ ), and also in terms of aerosol composition. Considering these results and the well-established ability of MADE in reproducing observed aerosol loadings and composition, MADE3 seems suitable for application within a global model.

\section{Introduction}

Aerosol particles affect the energy balance of the Earth both directly by scattering or absorbing radiation and indirectly by acting as cloud condensation nuclei. The present-day net effect of these processes is probably a negative radiative forcing $(\mathrm{RF})$ with respect to preindustrial times (e.g. Forster et al., 2007; Bellouin et al., 2013; Naik et al., 2013). Hence, the concurrent positive forcing by long-lived greenhouse gases may be partly offset by the aerosol forcing.

Global model simulations have indicated that the emissions from ocean ship traffic may be one of the largest contributors to the anthropogenic aerosol forcing (Lauer et al., 2007, 2009; Righi et al., 2011, 2013; Olivié et al., 2012; Peters et al., 2012, 2013). That contribution is mainly caused by the sulfur in the ship exhaust plumes that leads to the 
formation of aerosol sulfate $\left(\mathrm{SO}_{4}\right)$. Both nucleation of new particles and condensation of sulfuric acid $\left(\mathrm{H}_{2} \mathrm{SO}_{4}\right)$ vapour on emitted as well as on background particles contribute to $\mathrm{SO}_{4}$ formation.

The International Maritime Organization (IMO) has set limits on allowed shipping fuel sulfur content that will be further tightened in the future (IMO, 2011) in order to improve air quality in port cities and along coasts. On the one hand, the sulfur reduction leads to a decrease of aerosol $\mathrm{SO}_{4}$ concentrations (Lauer et al., 2009; Righi et al., 2011; Johansson et al., 2013). On the other hand, the reduced $\mathrm{SO}_{4}$ concentrations allow more aerosol nitrate $\left(\mathrm{NO}_{3}\right)$ formation by condensation of nitric acid $\left(\mathrm{HNO}_{3}\right)$. Increased $\mathrm{NO}_{3}$ content was shown to make up for a substantial fraction of the $\mathrm{SO}_{4}$ reduction (Lauer et al., 2009; Bellouin et al., 2011; Righi et al., 2011). The aerosol RF and total particulate mass concentrations may therefore not be reduced as much as the $\mathrm{SO}_{4}$ concentrations.

A number of measurements suggest that aerosol $\mathrm{NO}_{3}$ may primarily partition to the coarse mode both under clean marine conditions and when marine aerosol is affected by anthropogenic pollution (Kerminen et al., 1997; Hara et al., 1999; Yeatman et al., 2001; Cavalli et al., 2004; Nolte et al., 2008). However, in the assessment of the ship emissions' effects on climate by Peters et al. (2012, 2013), $\mathrm{NO}_{3}$ formation was not included at all, and the low-sulfur shipping fuel studies by Lauer et al. (2009) and Righi et al. (2011) did not include interactions of condensable gases with coarse mode particles (except for water vapour). These deficiencies may have led to errors in the quantification of low-sulfur fuel effects.

To improve on the previous investigations, we developed the new aerosol submodel MADE3 for use within the MESSy framework (Jöckel et al., 2005, 2010). Via this framework, MADE3 can be coupled to an atmospheric chemistry scheme and to the general circulation model ECHAM5 (Roeckner et al., 2006), which together form the atmospheric chemistry general circulation model (AC-GCM) EMAC (ECHAM5/MESSy2 atmospheric chemistry model). MADE3 is based on MADE (Ackermann et al., 1998; Lauer et al., 2005) and MADE-in (Aquila et al., 2011), but for the first time includes interactions of coarse mode particles with both condensable gases and other particles. To enable the further extension we restructured and improved major parts of the submodel code. Our main motivation for the development of MADE3 is a reassessment of the aerosol perturbations caused by global ship traffic under current and future scenarios for fuel sulfur content.

Some essential processes, e.g. particle transport and deposition, are not included in MADE3 because they are treated by other submodels within the MESSy framework. It is therefore not feasible to evaluate a stand-alone (box model) setup of MADE3 by comparison with measured data. Instead, we test here the algorithms used in MADE3 for solving the aerosol microphysics equations. In order to assess improvements, strengths, and weaknesses of the new submodel, we compare it to its predecessor MADE and to the particle-resolved stand-alone aerosol model PartMCMOSAIC (Riemer et al., 2009; Zaveri et al., 2008) in a box model application. For that purpose we define a marine background setup with added emissions representative of heavy ship traffic. We use MADE for comparison because previous studies on the shipping effect were carried out with this submodel (Lauer et al., 2007, 2009; Righi et al., 2011, 2013). PartMC-MOSAIC is regarded as a reference to test how well MADE3 performs as a solver for the aerosol dynamics equation. Implementation and evaluation of MADE3 within EMAC will be the subject of a follow-up study.

This paper is organised as follows: in Sect. 2 we first describe MADE3 in detail, then briefly state the most important improvements with respect to its predecessor MADE, and finally summarise the main features of PartMC-MOSAIC with a focus on the differences to MADE3. Section 3 contains the definition of our marine boundary layer test case. We report and discuss the results of the simulations with this setup in Sect. 4. Finally, in Sect. 5, we summarise our findings and present the conclusions.

\section{Model description}

We use the term "aerosol (sub)model" here to refer to the computer code used to solve the aerosol dynamics equation. Generally speaking, aerosol dynamics includes emissions, gas-to-particle conversion, transport, physical and chemical processing, and deposition of particles. Throughout this paper we focus on internal processes, i.e. those that are actually calculated by the aerosol submodel MADE3. These processes include gas-particle partitioning of semi-volatile species, condensation of nonvolatile $\mathrm{H}_{2} \mathrm{SO}_{4}$, formation of secondary organics, new particle formation by nucleation, and particle coagulation. We add emissions here in order to test the reaction of the internal processes to external perturbations. Transport and loss processes are excluded because they are treated by other submodels within the MESSy framework.

The aerosol dynamics equation thus takes on the following general form (nomenclature based on Riemer et al., 2009): 
$\frac{\partial n^{*}(\boldsymbol{\mu}, t)}{\partial t}=$

$\underbrace{\frac{1}{2} \int_{0}^{\mu_{1}} \int_{0}^{\mu_{2}} \cdots \int_{0}^{\mu_{A}} K\left(\boldsymbol{\mu}^{\prime}, \boldsymbol{\mu}-\boldsymbol{\mu}^{\prime}\right) n^{*}\left(\boldsymbol{\mu}^{\prime}, t\right) n^{*}\left(\boldsymbol{\mu}-\boldsymbol{\mu}^{\prime}, t\right) d \mu_{1}^{\prime} d \mu_{2}^{\prime} \ldots d \mu_{A}^{\prime}}$

coagulation gain

$-\underbrace{\int_{0}^{\infty} \int_{0}^{\infty} \cdots \int_{0}^{\infty} K\left(\boldsymbol{\mu}, \boldsymbol{\mu}^{\prime}\right) n^{*}(\boldsymbol{\mu}, t) n^{*}\left(\boldsymbol{\mu}^{\prime}, t\right) d \mu_{1}^{\prime} d \mu_{2}^{\prime} \ldots d \mu_{A}^{\prime}}$

coagulation loss

$$
\begin{aligned}
& -\underbrace{\sum_{i=1}^{C} \frac{\partial}{\partial \mu_{i}}\left(I_{i}(\boldsymbol{\mu}, \boldsymbol{g}, t) n^{*}(\boldsymbol{\mu}, t)\right)}_{\text {condensation/evaporation }}-\underbrace{\frac{\partial}{\partial \mu_{C+1}}\left(I_{\mathrm{W}}(\boldsymbol{\mu}, \boldsymbol{g}, t) n^{*}(\boldsymbol{\mu}, t)\right)}_{\text {water transfer }} \\
& +\underbrace{\dot{n}_{\text {nuc }}^{*}(\boldsymbol{\mu}, t)}_{\text {nucleation }}+\underbrace{\dot{n}_{\text {emit }}^{*}(\boldsymbol{\mu}, t)}_{\text {emission }} .
\end{aligned}
$$

Each aerosol particle is described by a vector $\boldsymbol{\mu}$ composed of the masses $\mu_{a}$ of the species $a=1, \ldots, A$. The number distribution of these particles (defined in the $A$-dimensional "species space") is given by

$n^{*}(\boldsymbol{\mu}, t)=\frac{\partial^{A} N^{*}(\boldsymbol{\mu}, t)}{\partial \mu_{1} \partial \mu_{2} \ldots \partial \mu_{A}}$,

where $N^{*}(\boldsymbol{\mu}, t)$ is the cumulative number concentration of particles containing less than the mass $\mu_{a}$ of species $a$. The two coagulation terms (i.e. gain and loss) are calculated based on the collision probability $K\left(\boldsymbol{\mu}_{\mathbf{1}}, \boldsymbol{\mu}_{2}\right)$ of particles described by the vectors $\boldsymbol{\mu}_{\mathbf{1}}$ and $\boldsymbol{\mu}_{\mathbf{2}}$. The per-particle flux of condensable gases between the gas and the condensed phase is $I_{i}(\boldsymbol{\mu}, \boldsymbol{g}, t)$ where $i=\mathrm{w}$ stands for water vapour and the vector $\boldsymbol{g}$ describes the gas composition. The components of the gas phase vector are the concentrations $g_{i}$ of the $i=1, \ldots, G$ different gas species. Condensable gases, i.e. the ones considered here, are assumed to be the first $i=1, \ldots, C$ of these species and correspond to the first $a=1, \ldots, C$ aerosol species. The species $C+1$ is assumed to be water vapour or liquid water, respectively. The number distribution production rates $\dot{n}_{\text {nuc }}^{*}(\boldsymbol{\mu}, t)$ and $\dot{n}_{\text {emit }}^{*}(\boldsymbol{\mu}, t)$ describe the addition of new particles by nucleation and emission, respectively.

\subsection{MADE3}

MADE3 is based on MADE-in (Aquila et al., 2011), an extension of MADE as described by Lauer et al. (2005). The first generation of MADE was developed for application in a regional model (Ackermann et al., 1998). It was derived from work by Whitby et al. (1991) and Binkowski and Shankar (1995). Subsequently, MADE was adapted for global applications and implemented into the general circulation model ECHAM4 by Lauer et al. (2005), and later transformed into a submodel (Lauer et al., 2007) for the MESSy framework. The second generation submodel MADE-in was developed by Aquila et al. (2011) as an extension to the MADE version used by Lauer et al. (2007). It was created to enable simulation of number concentrations and mixing states of particles containing the insoluble components black carbon and mineral dust. For the first version of the third generation submodel MADE3, we extended the microphysical calculations to also take into account coarse mode particles, which were formerly regarded as passive. For version $2.0 \mathrm{~b}$, we also extended the gas-particle partitioning scheme. The "b" stands for beta, which we include in the version number because MADE3 has not yet been tested as part of the 3-D model. Hence, some minor changes may still be required to reach a fully operational version 2.0 .

Despite substantial restructuring of the code during the development of MADE3 and the addition of new features, the third generation submodel still shares with MADE most of its features and the concepts underlying the computer code. The following sections are meant to serve as a reference for the mathematics on which the new submodel is based.

\subsubsection{Aerosol properties}

Different numerical representations of the number distribution function $n^{*}(\boldsymbol{\mu}, t)$ are used in aerosol (sub)models, depending on the available computational resources, i.e. on the target application. A very accurate representation is to track particles individually, as is done in PartMC-MOSAIC (see Sect. 2.3). However, if $N_{\mathrm{p}}$ particles are tracked individually, the condensation/evaporation terms in Eq. (1), for instance, have to be calculated $N_{\mathrm{p}}$ times. To adequately represent the whole size range of atmospheric particles, $N_{\mathrm{p}}$ has to be of the order of $10^{5}$. The computational cost of such an approach is prohibitive for application in an AC-GCM such as EMAC. Therefore, the number distribution $n^{*}(\boldsymbol{\mu}, t)$ is represented in MADE3 in a simplified manner, namely using the so-called modal approach. Instead of individual particle component masses, the characteristic variable is taken to be particle diameter, and the number distribution is approximated by a superposition of nine modes, i.e. nine lognormal functions $n_{k}(\ln \tilde{D}, t)$ in diameter space $(k=1, \ldots, 9$ is the mode index):

$$
\begin{aligned}
n(\ln \tilde{D}, t) & =\frac{\partial N(\ln \tilde{D}, t)}{\partial \ln \tilde{D}} \\
& =\sum_{k=1}^{9} n_{k}(\ln \tilde{D}, t) \\
& =\sum_{k=1}^{9} \frac{N_{k}(t)}{\sqrt{2 \pi} \ln \sigma_{k}} e^{-\frac{\left[\ln \tilde{D}-\ln \tilde{D}_{\mathrm{g}, k}(t)\right]^{2}}{2\left(\ln \sigma_{k}\right)^{2}}},
\end{aligned}
$$

where $N(\ln \tilde{D}, t)$ is the cumulative number concentration of particles with diameters smaller than $\tilde{D}$. The tilde (as in $\tilde{D})$ is used to indicate that the diameter was made dimensionless by division by $1 \mu \mathrm{m}$. Each mode $k$ is described by three parameters, namely the number concentration $N_{k}(t)$ of particles in 
Table 1. Parameters used in MADE3: mode widths, bulk aerosol component densities, accommodation coefficients for gas adsorption on aerosol particles, and diffusivities of gases in air. Abbreviations are as follows: POM for particulate organic matter, BC for black carbon, DU for mineral dust, and SOA for secondary organic aerosol.

\begin{tabular}{|c|c|c|c|}
\hline & Symbol & Value & Unit \\
\hline \multicolumn{4}{|l|}{ Mode widths } \\
\hline Soluble Aitken & $\sigma_{1}$ & 1.7 & \\
\hline Mixed Aitken & $\sigma_{2}$ & 1.7 & \\
\hline Insoluble Aitken & $\sigma_{3}$ & 1.7 & \\
\hline Soluble accumulation & $\sigma_{4}$ & 2.0 & \\
\hline Mixed accumulation & $\sigma_{5}$ & 2.0 & \\
\hline Insoluble accumulation & $\sigma_{6}$ & 2.0 & \\
\hline Soluble coarse & $\sigma_{7}$ & 2.2 & \\
\hline Mixed coarse & $\sigma_{8}$ & 2.2 & \\
\hline Insoluble coarse & $\sigma_{9}$ & 2.2 & \\
\hline \multicolumn{4}{|l|}{ Component densities } \\
\hline $\mathrm{SO}_{4}$ & $\rho_{\mathrm{SO}_{4}}$ & $1.8 \times 10^{3}$ & $\mathrm{~kg} \mathrm{~m}^{-3}$ \\
\hline $\mathrm{NH}_{4}$ & $\rho_{\mathrm{NH}_{4}}$ & $1.8 \times 10^{3}$ & $\mathrm{~kg} \mathrm{~m}^{-3}$ \\
\hline $\mathrm{NO}_{3}$ & $\rho_{\mathrm{NO}_{3}}$ & $1.8 \times 10^{3}$ & $\mathrm{~kg} \mathrm{~m}^{-3}$ \\
\hline $\mathrm{Na}$ & $\rho_{\mathrm{Na}}$ & $2.2 \times 10^{3}$ & $\mathrm{~kg} \mathrm{~m}^{-3}$ \\
\hline $\mathrm{Cl}$ & $\rho_{\mathrm{Cl}}$ & $2.2 \times 10^{3}$ & $\mathrm{~kg} \mathrm{~m}^{-3}$ \\
\hline POM & $\rho_{\mathrm{POM}}$ & $1.0 \times 10^{3}$ & $\mathrm{~kg} \mathrm{~m}^{-3}$ \\
\hline $\mathrm{BC}$ & $\rho_{\mathrm{BC}}$ & $2.2 \times 10^{3}$ & $\mathrm{~kg} \mathrm{~m}^{-3}$ \\
\hline DU & $\rho_{\mathrm{DU}}$ & $2.5 \times 10^{3}$ & $\mathrm{~kg} \mathrm{~m}^{-3}$ \\
\hline $\mathrm{H}_{2} \mathrm{O}$ & $\rho_{\mathrm{H}_{2} \mathrm{O}}$ & $1.0 \times 10^{3}$ & $\mathrm{~kg} \mathrm{~m}^{-3}$ \\
\hline \multicolumn{4}{|c|}{ Accommodation coefficients } \\
\hline $\mathrm{H}_{2} \mathrm{SO}_{4}$ & $\alpha_{\mathrm{H}_{2} \mathrm{SO}_{4}}$ & 1.0 & \\
\hline $\mathrm{NH}_{3}$ & $\alpha_{\mathrm{NH}_{3}}$ & 0.1 & \\
\hline $\mathrm{HNO}_{3}$ & $\alpha_{\mathrm{HNO}_{3}}$ & 0.1 & \\
\hline $\mathrm{HCl}$ & $\alpha_{\mathrm{HCl}}$ & 0.1 & \\
\hline SOA & $\alpha_{\mathrm{SOA}}$ & 1.0 & \\
\hline \multicolumn{4}{|l|}{ Gas diffusivities } \\
\hline $\mathrm{H}_{2} \mathrm{SO}_{4}$ & $\Delta_{\mathrm{H}_{2} \mathrm{SO}_{4}}$ & 0.09 & $\mathrm{~cm}^{2} \mathrm{~s}^{-1}$ \\
\hline $\mathrm{NH}_{3}$ & $\Delta \mathrm{NH}_{3}$ & 0.1 & $\mathrm{~cm}^{2} \mathrm{~s}^{-1}$ \\
\hline $\mathrm{HNO}_{3}$ & $\Delta_{\mathrm{HNO}_{3}}$ & 0.1 & $\mathrm{~cm}^{2} \mathrm{~s}^{-1}$ \\
\hline $\mathrm{HCl}$ & $\Delta_{\mathrm{HCl}}$ & 0.1 & $\mathrm{~cm}^{2} \mathrm{~s}^{-1}$ \\
\hline SOA & $\Delta_{\mathrm{SOA}}$ & 0.05 & $\mathrm{~cm}^{2} \mathrm{~s}^{-1}$ \\
\hline
\end{tabular}

that mode, its median particle diameter (geometric mean diameter) $D_{\mathrm{g}, k}(t)$, and its width (geometric standard deviation) $\sigma_{k}$. Note that we do not write out time dependencies explicitly in the remainder of this paper. Mode widths are fixed in MADE3 (as was the case for its predecessors) in order to further reduce the computational burden of the submodel. The values of $\sigma_{k}$ are listed in Table 1. All particles in one mode $k$ are assumed to have the same composition, i.e. the mass fractions $c_{a, k} / \sum_{s=1}^{A} c_{s, k}$ are the same for these particles. The symbol $c_{a, k}\left(c_{s, k}\right)$ denotes the mass concentration of species $a(s)$ in mode $k$ per unit volume of air.
Information about particle composition is lost in the size distribution representation as given by Eq. (3). Hence, we also track the mass concentrations $c_{a, k}$ as described in the next subsection. In MADE3 the number of equations to be solved is thus $9 \times(1+A)$, i.e. one equation for the number concentration $\left(N_{k}\right)$ per mode and $A$ equations for the different aerosol component species $\left(c_{a, k}\right)$ per mode. With $A=9$ species only 90 equations are required in MADE3 instead of $N_{\mathrm{p}} \sim 10^{5}$ in PartMC-MOSAIC to solve the aerosol dynamics equation (Eq. 1). The median diameter $D_{\mathrm{g}, k}$ of mode $k$ can be derived from the component mass concentrations $c_{a, k}$ in that mode under the assumption of spherical particles $\left(\rho_{a}\right.$ is the density of species $a$, see Table 1):

$D_{\mathrm{g}, k}=\left(\frac{6 V_{k}}{\pi N_{k}} e^{-\frac{9}{2}\left(\ln \sigma_{k}\right)^{2}}\right)^{\frac{1}{3}}$

with

$V_{k}=\sum_{a=1}^{A} \frac{c_{a, k}}{\rho_{a}}$

being the particle volume concentration of mode $k$.

Integral moments of the lognormal distribution are often used in the internal MADE3 computations to facilitate the calculations described in the following subsection. The $j$ th moment of mode $k$ is defined as

$$
\begin{aligned}
M_{j, k} & =\int_{-\infty}^{\infty} \tilde{D}^{j} \cdot 1 \mu \mathrm{m}^{j} \cdot n_{k}(\ln \tilde{D}) \mathrm{d} \ln \tilde{D} \\
& =N_{k} \cdot\left(D_{\mathrm{g}, k}\right)^{j} e^{\frac{j^{2}}{2}\left(\ln \sigma_{k}\right)^{2}} .
\end{aligned}
$$

The 0th moment is a mode's number concentration $\left(N_{k}\right)$, the second moment is related to its particle surface area concentration, and the third moment is related to the mode's particle volume concentration $\left(V_{k}=\pi \cdot M_{3, k} / 6\right.$, see also Eq. 5). These moments are used, for instance, to calculate coagulation and condensation rates (Whitby et al., 1991; Lauer et al., 2005; Aquila et al., 2011).

The nine modes in MADE3 (Fig. 1) are representative of three size ranges: the Aitken (tens of nanometres), accumulation (hundreds of nanometres), and coarse modes (micrometres). In each size range MADE3 includes one mode of fully soluble particles, one mode of insoluble particles and one mixed mode. The choice of this set of aerosol modes follows the ideas presented by Aquila et al. (2011), now extended to cover also the coarse mode size range.

Particles in MADE3 consist of up to nine different components, sometimes also called tracers, as they may represent more than one chemical species (Fig. 1, Table 1): sulfate $\left(\mathrm{SO}_{4}\right)$, ammonium $\left(\mathrm{NH}_{4}\right)$, nitrate $\left(\mathrm{NO}_{3}\right)$, a tracer that contains sea spray components other than chloride (named $\mathrm{Na}$ ), chloride $(\mathrm{Cl})$, particulate organic matter (POM), black carbon $(B C)$, mineral dust (DU), and water $\left(\mathrm{H}_{2} \mathrm{O}\right)$. Note that we 


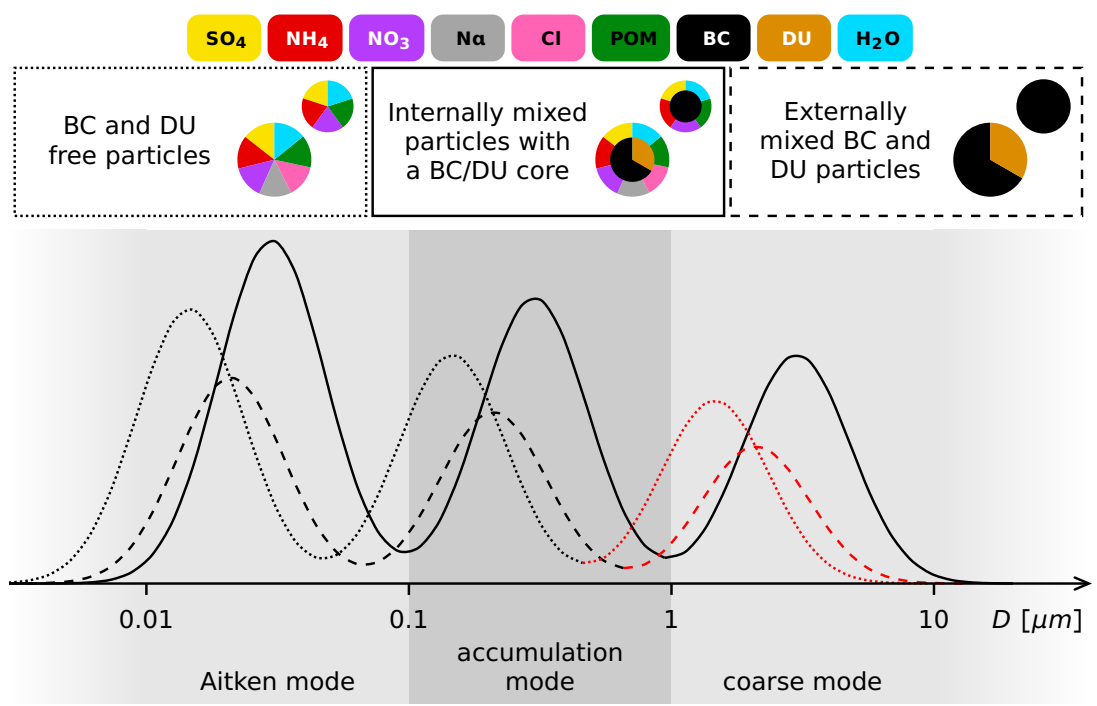

Figure 1. Schematic illustration of the MADE3 modes and aerosol composition. Each size range (Aitken, accumulation, and coarse mode size range) is represented by three modes: soluble (dotted lines), insoluble (dashed lines), and mixed particles (solid lines). Red lines indicate the new modes in MADE3 with respect to its predecessor MADE-in. Small "pie charts" show possible Aitken mode particle compositions, larger "pie charts" stand for accumulation and coarse mode particles. Note that the MADE3 code in principle allows all components in each of the modes, but some components do not appear in significant amounts in certain types of particles in the real atmosphere (e.g. mineral dust in Aitken mode particles). Abbreviations are as follows: POM for particulate organic matter, BC for black carbon, and DU for mineral dust.

do not add charges to the tracer names here because we do not distinguish between different oxidation and phase states of the aerosol components. For instance, the $\mathrm{SO}_{4}$ tracer includes $\mathrm{SO}_{4}^{2-}, \mathrm{HSO}_{4}^{-}$, and liquid $\mathrm{H}_{2} \mathrm{SO}_{4}$, as well as the sulfate in $\left(\mathrm{NH}_{4}\right)_{2} \mathrm{SO}_{4}$ and other crystalline salts.

\subsubsection{Aerosol processes}

Particle composition, number concentration, and size distribution undergo changes during the atmospheric processing of the aerosol. MADE3 calculates the evolution of the particle population due to three main processes: (1) gas-particle partitioning of semi-volatile species and water, which adds or removes particulate mass depending on environmental parameters (such as temperature or relative humidity); (2) gasto-particle conversion of low-volatility species by condensation on pre-existing particles or in situ formation of new particles; (3) mass transfer between particles by coagulation, which concurrently reduces particle number concentration. Employing an operator splitting approach, MADE3 first calculates compositional changes due to gas-particle partitioning alone. Subsequently, condensation/new particle formation and coagulation are treated simultaneously.

\section{Gas-particle partitioning}

Gas-particle partitioning of semi-volatile trace constituents $\left(\mathrm{NH}_{3} / \mathrm{NH}_{4}, \mathrm{HNO}_{3} / \mathrm{NO}_{3}, \mathrm{HCl} / \mathrm{Cl}\right)$ and water is calculated in MADE3 using the thermodynamic equilibrium model EQSAM (EQuilibrium Simplified Aerosol Model; Metzger et al., 2002, 2006). A sequential treatment of the three size ranges is applied in analogy to the procedure adopted by Aquila et al. (2011). The assumption of equilibrium between the gas and condensed phases is well justified for fine particles because they equilibrate on timescales of the order of seconds up to a few minutes (e.g. Meng and Seinfeld, 1996), i.e. well within the typical time step used for aerosol studies with $\mathrm{EMAC}\left(\sim 30 \mathrm{~min}\right.$ in $\mathrm{T} 42$ resolution, i.e. $\left.\approx 2.8^{\circ} \times 2.8^{\circ}\right)$.

For large particles (in the size range of micrometres and greater), however, gas diffusion may be too slow to enable equilibration within this time frame (e.g. Wexler and Seinfeld, 1990, 1992; Meng and Seinfeld, 1996). Hence, the equilibrium assumption may introduce substantial errors (Moya et al., 2002; Koo et al., 2003; Feng and Penner, 2007; Athanasopoulou et al., 2008), but fully dynamical calculations of the involved fluxes are infeasible in long-term simulations with AC-GCMs. Several solutions to this problem have been proposed (Capaldo et al., 2000; Pilinis et al., 2000; Jacobson, 2005; Zaveri et al., 2008). However, most of them are still computationally too expensive for application in MADE3 within EMAC, and the solution by Zaveri et al. (2008) would require a complete revision of the chemistry scheme that was used in previous simulations with MADE (e.g. Lauer et al., 2007; Aquila et al., 2011; Righi et al., 2011, 2013). Consequently, we account for possible non-equilibrium effects by limiting the gas-particle fluxes involving coarse mode particles in a similar manner as described by Pringle et al. (2010a); Pringle et al. (2010b). We calculate the maximum possible diffusion fluxes of the semivolatile gases (using equations equivalent to Eqs. (8) and (9) 
with $g_{X, \mathrm{~s}}=0$, see below) and perform an equilibrium calculation with EQSAM. If the fluxes required to reach this equilibrium surpass the maximum fluxes, we limit the amount of material that condenses during one time step accordingly.

\section{Condensation of $\mathrm{H}_{2} \mathrm{SO}_{4}$ and organic vapours}

Due to its very low equilibrium vapour pressure, we assume that all $\mathrm{H}_{2} \mathrm{SO}_{4}$ is transferred from the gas phase to the aerosol phase during each time step. Depending on the magnitude of the condensation flux, this transfer can occur via condensation alone, or via condensation and new particle formation (see below). To determine the amount of $\mathrm{H}_{2} \mathrm{SO}_{4}$ that can condense during one time step, we calculate the condensation flux explicitly. This is also necessary to obtain the proper distribution of the condensate among the differently sized particles. An equilibrium assumption does not yield this distribution. While potential errors in the distribution of condensing material among differently sized particles will be corrected by re-evaporation in the case of the semi-volatile species, this is not possible for $\mathrm{H}_{2} \mathrm{SO}_{4}$, since our assumption that all $\mathrm{H}_{2} \mathrm{SO}_{4}$ is transferred to the aerosol phase means that it cannot re-evaporate in our model. The total condensation flux of $\mathrm{H}_{2} \mathrm{SO}_{4}$ is the sum of the rates of change of mass concentrations $c_{\mathrm{H}_{2} \mathrm{SO}_{4}, k}$ for all modes $(k=1, \ldots, 9)$ :

$$
\left(\frac{\mathrm{d} c_{\mathrm{H}_{2} \mathrm{SO}_{4}, k}}{\mathrm{~d} t}\right)_{\text {cond }}=\int_{0}^{\infty} \frac{\mathrm{d} m_{\mathrm{p}}(D)}{\mathrm{d} t} n_{k}(D) \mathrm{d} D,
$$

where $\mathrm{d} m_{\mathrm{p}}(D) / \mathrm{d} t$ is the rate of change of mass for an individual particle of diameter $D$ and $n_{k}(D) \mathrm{d} D=$ $n_{k}(\ln \tilde{D}) \mathrm{d} \ln \tilde{D}$. Note that with $\mathrm{d} \ln \tilde{D} / \mathrm{d} D=1 / D$ one obtains $n_{k}(\ln \tilde{D}) / D$ as the functional form for $n_{k}(D)$, where $n_{k}(\ln \tilde{D})$ has to be inserted as given in Eq. (3). The rate of particle mass change depends on the ratio of the particle diameter $D$ and the mean free path $\lambda$ of $\mathrm{H}_{2} \mathrm{SO}_{4}$ molecules in the gas phase. As atmospheric aerosol particles span a large range of sizes, two limiting cases have to be considered. In the continuum regime, i.e. for $D \gg \lambda$, one obtains (see Seinfeld and Pandis, 2006)

$$
\left(\frac{\mathrm{d} m_{\mathrm{p}}(D)}{\mathrm{d} t}\right)^{\mathrm{cont}}=2 \pi D \Delta_{\mathrm{H}_{2} \mathrm{SO}_{4}}\left(g_{\mathrm{H}_{2} \mathrm{SO}_{4}, \infty}-g_{\mathrm{H}_{2} \mathrm{SO}_{4}, \mathrm{~s}}\right)
$$

with the gas phase diffusivity $\Delta_{\mathrm{H}_{2} \mathrm{SO}_{4}}$ (see Table 1). The additional indices " $\infty$ " and "s" specify gas phase concentrations far away from the particle surface and directly above it, respectively. The corresponding expression for the kinetic, or free molecular, regime where $D \ll \lambda$ is (Seinfeld and Pandis, 2006)

$$
\begin{aligned}
& \left(\frac{\mathrm{d} m_{\mathrm{p}}(D)}{\mathrm{d} t}\right)^{\text {free }}= \\
& \quad \frac{\pi D^{2}}{4} \alpha_{\mathrm{H}_{2} \mathrm{SO}_{4}} \omega_{\mathrm{H}_{2} \mathrm{SO}_{4}}\left(g_{\mathrm{H}_{2} \mathrm{SO}_{4}, \infty}-g_{\mathrm{H}_{2} \mathrm{SO}_{4}, \mathrm{~s}}\right) .
\end{aligned}
$$

Here, $\alpha_{\mathrm{H}_{2} \mathrm{SO}_{4}}$ is the accommodation coefficient (see Table 1) and $\omega_{\mathrm{H}_{2} \mathrm{SO}_{4}}$ the thermal speed of the $\mathrm{H}_{2} \mathrm{SO}_{4}$ molecules:

$\omega_{\mathrm{H}_{2} \mathrm{SO}_{4}}=\sqrt{\frac{8 R T}{\pi M_{\mathrm{H}_{2} \mathrm{SO}_{4}}}}$,

where $R$ is the universal gas constant, $T$ the absolute temperature, and $M_{\mathrm{H}_{2} \mathrm{SO}_{4}}$ the molar mass of $\mathrm{H}_{2} \mathrm{SO}_{4}$. Note that a wide range of values for $\alpha_{\mathrm{H}_{2} \mathrm{SO}_{4}}$ has been derived from measurements (0.02-0.79; e.g. Van Dingenen and Raes, 1991; Kerminen and Wexler, 1995; Jefferson et al., 1997; Bardouki et al., 2003) and used in models (0.1-1; e.g. Capaldo et al., 2000; Vignati et al., 2004; Zaveri et al., 2008; Mann et al., 2010; Kajino et al., 2012). Here, we use $\alpha_{\mathrm{H}_{2} \mathrm{SO}_{4}}=1$ as in former generations of the submodel, which was also found to be in agreement with field measurements by Eisele and Tanner (1993). The value is the same for all modes, i.e. condensation is treated in the same way, regardless of whether particles contain insoluble material or not. We set $g_{\mathrm{H}_{2} \mathrm{SO}_{4}, \mathrm{~s}}=0$ due to the very low equilibrium vapour pressure of $\mathrm{H}_{2} \mathrm{SO}_{4}$. For $g_{\mathrm{H}_{2} \mathrm{SO}_{4}, \infty}$ we use the solution to the ordinary differential equation that describes the temporal evolution of the gas phase $\mathrm{H}_{2} \mathrm{SO}_{4}$ concentration $g_{\mathrm{H}_{2} \mathrm{SO}_{4}}$ :

$\frac{\mathrm{d} g_{\mathrm{H}_{2} \mathrm{SO}_{4}}}{\mathrm{~d} t}=P_{\mathrm{H}_{2} \mathrm{SO}_{4}}-L_{\mathrm{H}_{2} \mathrm{SO}_{4}} \cdot g_{\mathrm{H}_{2} \mathrm{SO}_{4}}$.

Here, $P_{\mathrm{H}_{2} \mathrm{SO}_{4}}$ is the production rate of gaseous $\mathrm{H}_{2} \mathrm{SO}_{4}$ and $L_{\mathrm{H}_{2} \mathrm{SO}_{4}}$ is the sum of the integrals as given in Eq. (7) for all nine modes with the factor $g_{\mathrm{H}_{2} \mathrm{SO}_{4}, \infty}$ removed, i.e. the overall loss coefficient due to condensation:

$L_{\mathrm{H}_{2} \mathrm{SO}_{4}}=\frac{\sum_{k=1}^{9}\left(\frac{\mathrm{d} c_{\mathrm{H}_{2}} \mathrm{SO}_{4}, k}{\mathrm{~d} t}\right)_{\text {cond }}}{g_{\mathrm{H}_{2} \mathrm{SO}_{4}, \infty}}$.

Production of gaseous $\mathrm{H}_{2} \mathrm{SO}_{4}$ and condensation on the particles are thus considered in parallel.

The integral in Eq. (7) can be evaluated analytically with both expressions for $\mathrm{d} m_{\mathrm{p}}(D) / \mathrm{d} t$ (Whitby et al., 1991). However, there is also a transition regime, where $D$ and $\lambda$ are of the same order of magnitude. We therefore apply the method of Binkowski and Shankar (1995), using half the harmonic mean of the two integrals as the condensation rate of $\mathrm{H}_{2} \mathrm{SO}_{4}$ on mode $k$. For more details on the condensation calculations see the description in Appendix A of Aquila et al. (2011) or the original work by Whitby et al. (1991).

Secondary organic aerosol (SOA) formation from condensing organic vapours is treated in the same simplified manner in MADE3 as in MADE-in (Aquila et al., 2011). Using an externally supplied mass formation rate of SOA $\left(P_{\mathrm{SOA}}\right)$, we apply a similar procedure as outlined above for $\mathrm{H}_{2} \mathrm{SO}_{4}$ condensation. The SOA production rate is multiplied by the time step duration $\Delta t$ to obtain $g_{\mathrm{SOA}, \infty}$ for analogous expressions to Eqs. (8) and (9). The near-surface gas phase concentration is again set to zero $\left(g_{\mathrm{SOA}, \mathrm{s}}=0\right.$, neglecting semi-volatile organic species because organic gas phase 
chemistry is not considered) so that the integral in Eq. (7) can be evaluated just as for $\mathrm{H}_{2} \mathrm{SO}_{4}$.

\section{New particle formation}

Nucleation of new particles from $\mathrm{H}_{2} \mathrm{SO}_{4}$ and $\mathrm{H}_{2} \mathrm{O}$ is calculated in MADE3 after solving the production-condensation equation (Eq. 11). This approach corresponds to method $2 \mathrm{C}$ as discussed by Wan et al. (2013). In terms of the nucleation sink for gaseous $\mathrm{H}_{2} \mathrm{SO}_{4}$, they showed this method to be the best-performing among sequential methods for solving the full $\mathrm{H}_{2} \mathrm{SO}_{4}$ equation, i.e. Eq. (11) plus a nucleation loss term. To calculate the nucleation rate, $\left(\mathrm{d} N_{1} / \mathrm{d} t\right)_{\text {nuc }}$, we apply the parameterisation by Vehkamäki et al. $(2002,2013)$ that is based on temperature, relative humidity $(\mathrm{RH})$, and $\mathrm{H}_{2} \mathrm{SO}_{4}$ concentration. Following Binkowski and Roselle (2003), we account for rapid growth of the freshly nucleated particles to detectable sizes by assuming a monodisperse size distribution with $D=3.5 \mathrm{~nm}$ upon formation. The $\mathrm{H}_{2} \mathrm{SO}_{4}$ fraction of these particles is calculated from the ambient $\mathrm{RH}$ as described in Binkowski and Roselle (2003), based on measurements by Nair and Vohra (1975). Subsequently, number and mass concentrations of the nucleated particles are added to the soluble Aitken mode $(k=1)$. New particle formation from organic precursor gases is not considered in MADE3.

\section{Coagulation}

Similar to the condensation treatment, coagulation calculations in MADE3 are also performed by mode. Number and mass changes are calculated separately:

$$
\begin{aligned}
& \left(\frac{\mathrm{d} N_{k}}{\mathrm{~d} t}\right)_{\text {coag }}= \\
& \sum_{l=1}^{9} \sum_{m=l}^{9}\left(a_{l m}^{k} \cdot \int_{0}^{\infty} \int_{0}^{\infty} \beta\left(D_{1}, D_{2}\right) n_{l}\left(D_{1}\right) n_{m}\left(D_{2}\right) \mathrm{d} D_{1} \mathrm{~d} D_{2}\right), \\
& \left(\frac{\mathrm{d} c_{a, k}}{\mathrm{~d} t}\right)_{\text {coag }}=\frac{\pi}{6} \cdot \sum_{l=1}^{9} \sum_{m=l}^{9}\left[\left(\delta_{k, \tau_{l m}}-\delta_{k, l}\right) \cdot \frac{c_{a, l}}{\sum_{s=1}^{A} c_{s, l}}\right. \\
& \cdot \rho_{l} \cdot \int_{0}^{\infty} \int_{0}^{\infty}\left(D_{1}\right)^{3} \beta\left(D_{1}, D_{2}\right) n_{l}\left(D_{1}\right) n_{m}\left(D_{2}\right) \mathrm{d} D_{1} \mathrm{~d} D_{2} \\
& +\left(\delta_{k, \tau_{l m}}-\delta_{k, m}\right) \cdot \frac{c_{a, m}}{\sum_{s=1}^{A} c_{s, m}} \\
& \left.\cdot \rho_{m} \cdot \int_{0}^{\infty} \int_{0}^{\infty}\left(D_{2}\right)^{3} \beta\left(D_{1}, D_{2}\right) n_{l}\left(D_{1}\right) n_{m}\left(D_{2}\right) \mathrm{d} D_{1} \mathrm{~d} D_{2}\right] .
\end{aligned}
$$

The parameters $\rho_{l}$ and $\rho_{m}$ in Eq. (14) stand for the densities of particles in modes $l$ and $m$, respectively. The coefficients $a_{l m}^{k}$ are calculated as follows:

$a_{l m}^{k}=\delta_{k, \tau_{l m}} \cdot\left(1+\frac{\delta_{l, m}}{2}\right)-\delta_{k, l}-\delta_{k, m}$.

Here, as in Eq. (14), the Kronecker symbol $\delta_{x, y}$ has been used. Its value is $\delta_{x, y}=1$ if $x=y$, and $\delta_{x, y}=0$ otherwise. The matrix elements $\tau_{l m}$ are used for the assignment of number and mass concentrations of coagulated particles to a target mode, depending on the modes of origin, $l$ and $m$. The rules for this assignment, i.e. the values of the matrix elements $\tau_{l m}$, follow Aquila et al. (2011):

- intramodal coagulation produces particles in the same $\operatorname{mode}\left(\tau_{l l}=l\right)$;

- intermodal coagulation produces particles in the size range of the larger mode;

- the exact target mode for intermodal coagulation depends on the mass fraction $x$ of soluble material and water in the final particles:

$$
\begin{aligned}
& x=1 \text { : soluble mode } \\
& 0.1 \leq x<1 \text { : mixed mode, } \\
& x<0.1 \text { : insoluble mode. }
\end{aligned}
$$

For instance, particles that result from intermodal coagulation of particles from modes $l=1$ (soluble Aitken mode, or "ks" in Table 2) and $m=4$ (soluble accumulation mode, or "as") are assigned to mode $\tau_{14}=4$ ("as"). Hence, $a_{14}^{4}=0$, which means that this process does not add to the particle number in mode $k=4$ ("as"). It does, however, add mass from mode $l=1$ ("ks") to mode $k=4$ ("as"). This is reflected in the parentheses with the Kronecker symbols in Eq. (14): the first pair of parentheses evaluates to one, the second pair to zero. In case of intramodal coagulation, i.e. if $l=k$ and $m=k$, the value of the coefficient in Eq. (13) is $a_{k k}^{k}=-0.5$. It is negative because one particle per such event is lost, but the factor is only -0.5 because of the double integration over the same mode. For intramodal coagulation, all the Kronecker symbols in Eq. (14) evaluate to one, so that all summands are zero, and no mass is added to, or removed from mode $k$.

In total, Eq. (13) and Eq. (14) include 45 and 90 summands for each mode $k$, respectively, but many of them are zeros. For example, coagulation losses and gains in the soluble coarse mode ("cs" in Table 2) are described by seven non-zero terms in the number equation (Eq. 13), and eight non-zero terms in the mass equation (Eq. 14).

For the Brownian coagulation kernel $\beta\left(D_{1}, D_{2}\right)$ we use the approximate formulations developed by Whitby et al. (1991) that can be integrated analytically. Two different expressions are required again, depending on the size of the 
Table 2. Matrix elements $\tau_{l m}$ (table cells) for assignment of particles that result from coagulation of particles from mode $l$ (row) with particles from mode $m$ (column). The mode naming convention is " $\mathrm{k}$ ", "a", "c" as a first letter to specify the Aitken, accumulation, or coarse mode, respectively, and "s", "m", "i" as a second letter for the soluble, mixed, or insoluble mode, respectively. Thus, the soluble coarse mode, for instance, is named "cs". Corresponding numbers are as follows: $\mathrm{ks}=1, \mathrm{~km}=2, \mathrm{ki}=3$, as $=4$, am $=5, \mathrm{ai}=6, \mathrm{cs}=7, \mathrm{~cm}=8$, and $\mathrm{ci}=9$.

\begin{tabular}{cccccccccc}
\hline & $\mathrm{ks}$ & $\mathrm{km}$ & $\mathrm{ki}$ & $\mathrm{as}$ & $\mathrm{am}$ & ai & $\mathrm{cs}$ & $\mathrm{cm}$ & $\mathrm{ci}$ \\
\hline $\mathrm{ks}$ & $\mathrm{ks}$ & $\mathrm{km}$ & $\mathrm{km} / \mathrm{ki}$ & as & $\mathrm{am}$ & $\mathrm{am} / \mathrm{ai}$ & $\mathrm{cs}$ & $\mathrm{cm}$ & $\mathrm{ci}$ \\
$\mathrm{km}$ & $\mathrm{km}$ & $\mathrm{km}$ & $\mathrm{km} / \mathrm{ki}$ & $\mathrm{am}$ & $\mathrm{am}$ & $\mathrm{am} / \mathrm{ai}$ & $\mathrm{cm}$ & $\mathrm{cm}$ & $\mathrm{ci}$ \\
$\mathrm{ki}$ & $\mathrm{km} / \mathrm{ki}$ & $\mathrm{km} / \mathrm{ki}$ & $\mathrm{ki}$ & $\mathrm{am} / \mathrm{ki}$ & $\mathrm{am} / \mathrm{ki}$ & ai & $\mathrm{cm}$ & $\mathrm{cm}$ & $\mathrm{ci}$ \\
$\mathrm{as}$ & $\mathrm{as}$ & $\mathrm{am}$ & $\mathrm{am} / \mathrm{ki}$ & $\mathrm{as}$ & $\mathrm{am}$ & $\mathrm{am} / \mathrm{ai}$ & $\mathrm{cs}$ & $\mathrm{cm}$ & $\mathrm{cm} / \mathrm{ci}$ \\
$\mathrm{am}$ & $\mathrm{am}$ & $\mathrm{am}$ & $\mathrm{am} / \mathrm{ki}$ & $\mathrm{am}$ & $\mathrm{am}$ & $\mathrm{am} / \mathrm{ai}$ & $\mathrm{cm}$ & $\mathrm{cm}$ & $\mathrm{cm} / \mathrm{ci}$ \\
$\mathrm{ai}$ & $\mathrm{am} / \mathrm{ai}$ & $\mathrm{am} / \mathrm{ai}$ & $\mathrm{ai}$ & $\mathrm{am} / \mathrm{ai}$ & $\mathrm{am} / \mathrm{ai}$ & $\mathrm{ai}$ & $\mathrm{cm} / \mathrm{ai}$ & $\mathrm{cm} / \mathrm{ai}$ & $\mathrm{ci}$ \\
$\mathrm{cs}$ & $\mathrm{cs}$ & $\mathrm{cm}$ & $\mathrm{cm}$ & $\mathrm{cs}$ & $\mathrm{cm}$ & $\mathrm{cm} / \mathrm{ai}$ & $\mathrm{cs}$ & $\mathrm{cm}$ & $\mathrm{cm} / \mathrm{ci}$ \\
$\mathrm{cm}$ & $\mathrm{cm}$ & $\mathrm{cm}$ & $\mathrm{cm}$ & $\mathrm{cm}$ & $\mathrm{cm}$ & $\mathrm{cm} / \mathrm{ai}$ & $\mathrm{cm}$ & $\mathrm{cm}$ & $\mathrm{cm} / \mathrm{ci}$ \\
$\mathrm{ci}$ & $\mathrm{ci}$ & $\mathrm{ci}$ & $\mathrm{ci}$ & $\mathrm{cm} / \mathrm{ci}$ & $\mathrm{cm} / \mathrm{ci}$ & $\mathrm{ci}$ & $\mathrm{cm} / \mathrm{ci}$ & $\mathrm{cm} / \mathrm{ci}$ & $\mathrm{ci}$ \\
\hline
\end{tabular}

particles. For the continuum regime the function is given as (Whitby et al., 1991)

$$
\begin{aligned}
\beta^{\mathrm{cont}}\left(D_{1}, D_{2}\right) & = \\
& \frac{2 k_{\mathrm{B}} T}{3 v} \cdot\left[2+2 \lambda A\left(\frac{1}{D_{1}}+\frac{D_{2}}{\left(D_{1}\right)^{2}}\right)\right. \\
+ & \left.2 \lambda A\left(\frac{1}{D_{2}}+\frac{D_{1}}{\left(D_{2}\right)^{2}}\right)+\frac{D_{2}}{D_{1}}+\frac{D_{1}}{D_{2}}\right]
\end{aligned}
$$

with Boltzmann's constant $k_{\mathrm{B}}$, atmospheric dynamic viscosity $v$, and the constant $A=1.246$ that accounts for the reduced drag on small particles. Atmospheric viscosity is calculated from temperature $(T)$ :

$v=B \cdot \frac{T^{\frac{3}{2}}}{T+S}$

with $B=1.458 \times 10^{-6} \mathrm{~kg} \mathrm{~m}^{-1} \mathrm{~s}^{-1} \mathrm{~K}^{-0.5}$ and $S=110.4 \mathrm{~K}$. The mean free path depends on both temperature and pressure:

$\lambda=\Lambda \cdot \frac{p_{0} T}{T_{0} p}$,

where $\Lambda=6.6328 \times 10^{-8} \mathrm{~m}, p_{0}=101325 \mathrm{~Pa}$, and $T_{0}=$ $288.15 \mathrm{~K}$. For the free molecular regime, the coagulation kernel becomes (Whitby et al., 1991)

$$
\begin{aligned}
& \beta^{\text {free }}\left(D_{1}, D_{2}\right)=\sqrt{\frac{6 k_{\mathrm{B}} T}{\rho_{1}+\rho_{2}}} \\
& \cdot\left(\sqrt{D_{1}}+2 \frac{D_{2}}{\sqrt{D_{1}}}+\frac{\left(D_{2}\right)^{2}}{\left(D_{1}\right)^{3 / 2}}+\frac{\left(D_{1}\right)^{2}}{\left(D_{2}\right)^{3 / 2}}+2 \frac{D_{1}}{\sqrt{D_{2}}}+\sqrt{D_{2}}\right),
\end{aligned}
$$

where $\rho_{1}\left(\rho_{2}\right)$ is the density of the particle with diameter $D_{1}$ $\left(D_{2}\right)$. Note that a correction factor is required for the integrals in Eqs. (13) and (14) if this kernel approximation for the free molecular regime is used. It is set constant at 0.8 for unimodal and 0.9 for bimodal coagulation in MADE3. After evaluation of the coagulation integrals for both regimes (i.e. with $\beta^{\text {cont }}\left(D_{1}, D_{2}\right)$ and $\beta^{\text {free }}\left(D_{1}, D_{2}\right)$, respectively) the halved harmonic means of the resulting rates are used to redistribute mass and numbers among the modes (see Appendix B in Aquila et al., 2011).

\section{Renaming}

As particles grow by condensation and coagulation, the Aitken modes may grow into the size range of the accumulation modes. In order to avoid mode merging, i.e. to keep the modes approximately within their assigned size ranges, we apply a procedure that is termed renaming (Binkowski and Roselle, 2003). One of two criteria must be met in MADE3 to trigger renaming within a time step. Either the volume growth rate of the Aitken mode must be larger than that of the corresponding accumulation mode, or the median diameter of the Aitken mode must exceed $30 \mathrm{~nm}$ and its number concentration must be greater than that of the corresponding accumulation mode. In such a case the number concentration of particles greater than the intersection diameter of the two number size distributions is shifted from the Aitken to the corresponding accumulation mode. The associated mass concentration is also transferred. Renaming is performed only between modes of the same particle type, i.e. either between the two soluble modes, or between the two insoluble modes, or between the two mixed modes. Note that we do not rename particles from the accumulation to the coarse modes because their diameters are changed much less by condensation and coagulation than those of the Aitken mode particles.

\section{Aging of insoluble particles}

The aerosol processing in the atmosphere is also termed aging. For insoluble particles this term often refers to the acquisition of a coating of soluble components that transforms them from an initially hydrophobic state to a hydrophilic one. In MADE3 this transformation is realised by transfer of number and mass concentrations from the insoluble modes to the mixed modes in analogy to the procedure described by 
Aquila et al. (2011). Following Aquila et al. (2011), we use a threshold mass concentration fraction of $10 \%$ of soluble material and water in an insoluble mode to trigger this transfer.

\subsection{MADE3 vs. MADE}

MADE is used here in the version described by Lauer et al. (2005). Although the code underwent major restructuring and was expanded for the development of MADE3 via MADE-in (Aquila et al., 2011), the new submodel still shares with MADE the computational approaches to aerosol size distribution representation, gas-particle partitioning, $\mathrm{H}_{2} \mathrm{SO}_{4}$ and SOA condensation, new particle formation, and coagulation. Here we therefore point out only the major physically motivated changes in MADE3 with respect to MADE.

The most obvious difference is in the number of modes, which increased from three (MADE) to nine (MADE3). The representation of aerosol particles by three modes per size range allows us to model both internally mixed particles and externally mixed particle populations (see Aquila et al., 2011).

Furthermore, while particles in the MADE coarse mode are considered passive (only water uptake by coarse mode particles is included), they interact with both other particles and condensable trace gases in MADE3. Coarse mode particle composition as well as effects of the coarse mode on fine particles and the gas phase can therefore be resolved in much more detail with MADE3 than what is feasible with MADE. Note also that coarse mode particles in MADE are composed of sea spray, mineral dust, and water only, while MADE3 allows all aerosol components to be present in the coarse modes.

In combination with the larger number of modes, the newly introduced interactions of coarse mode particles also entail a larger number of different possible coagulation pathways: 45 in MADE3 vs. 2 in MADE. The calculations to determine target modes based on the soluble mass fraction of the coagulated particles is not necessary in MADE, while it is required for 14 of the coagulation pathways in MADE3.

In addition, $\mathrm{Cl}$ is considered as a separate species in MADE3, whereas all sea spray components are lumped into one tracer in MADE. The explicit $\mathrm{Cl}$ representation enables the calculation of gas-aerosol partitioning for $\mathrm{HCl}$ by EQSAM, which is not considered in MADE, but is required for accurate modelling of processes in the marine boundary layer and in coastal areas.

With the larger number of modes, the inclusion of the coarse mode particle interactions, and the inclusion of the $\mathrm{Cl}$ tracer, the number of aerosol species tracers increased from 18 in MADE to 81 in MADE3.

\subsection{PartMC-MOSAIC}

PartMC-MOSAIC is a stochastic particle-resolved aerosol model that consists of the microphysics code PartMC (Particle-resolved Monte Carlo model, Riemer et al., 2009) and the gas and condensed phase chemical solver MOSAIC (MOdel for Simulating Aerosol Interactions and Chemistry, Zaveri et al., 2008). The PartMC-MOSAIC version used for the present study (v. 2.2.1) corresponds to the detailed description in Tian et al. (2014), so that we only give a brief summary of the relevant features here.

The model solves the aerosol dynamics equation (Eq. 1) on a per-particle basis. While the size distribution is constrained in MADE3 by the assumption of lognormal modes, it can freely evolve in PartMC-MOSAIC, where $n^{*}(\boldsymbol{\mu}, t)$ is represented by a finite number $N_{\mathrm{p}}$ of computational particles with discrete sizes. For the present study we chose $N_{\mathrm{p}} \approx 10^{5}$, as was done in previous applications of PartMC-MOSAIC (e.g. Riemer et al., 2009; Tian et al., 2014). In order to capture the large range of possible sizes and concentrations, one computational particle can represent a larger number of real particles (DeVille et al., 2011). The number and mass weighting of these computational particles for the microphysics and chemistry calculations is performed automatically. As particles are constantly emitted but loss processes are not considered here (except for coagulation), half of the particles are randomly picked out and discarded whenever the number of computational particles exceeds twice its initial value.

Aerosol composition can be resolved into more separate species in PartMC-MOSAIC than in MADE3. Here, we use 11 tracers: $\mathrm{SO}_{4}, \mathrm{NH}_{4}, \mathrm{NO}_{3}, \mathrm{Na}, \mathrm{Cl}$, organic carbon (OC), black carbon $(\mathrm{BC})$, calcium $(\mathrm{Ca})$, carbonate $\left(\mathrm{CO}_{3}\right)$, other inorganic material (OIN), and $\mathrm{H}_{2} \mathrm{O}$.

Particle emissions and coagulation are treated stochastically in PartMC. Random samples are added at each time step such that the number of emitted particles per unit time is Poisson distributed around a prescribed continuous mean emission rate. The composition and mean size distribution of these particles are also prescribed. For coagulation the maximum number of collision events during the time step is estimated and a corresponding number of candidate particle pairs is randomly selected. Subsequently, an accept-reject procedure is applied to determine whether these pairs actually coagulate. The probability for acceptance is based on the Brownian coagulation kernel.

Condensation of $\mathrm{H}_{2} \mathrm{SO}_{4}$ and gas-particle partitioning of semi-volatile gases is dynamically calculated by the deterministic model MOSAIC. This is in contrast to the equilibrium assumption in MADE3, so that no special treatment of large particles is required here. Note that, besides the different approaches to aerosol microphysics, the use of different codes for the thermodynamic calculations (EQSAM in MADE3 vs. MOSAIC in PartMC-MOSAIC) can be a major driver of differences in simulation results. 
The validity of the PartMC microphysics routines was demonstrated by Riemer et al. (2009) and MOSAIC was shown to perform well in comparison to other aerosol chemistry codes (Zaveri et al., 2008), which included more details than the treatment in MADE3. The combined model (PartMC-MOSAIC) was successfully applied in a recent study of a ship plume (Tian et al., 2014). In summary, PartMC-MOSAIC is able to capture many more details of the aerosol evolution than MADE3 and can therefore serve as a reference for our comparison.

\section{Test case setup}

We performed test simulations with MADE3, MADE and PartMC-MOSAIC using initial conditions representative of the marine background boundary layer. The setup was designed to mimic the actual target application of MADE3, namely its use within the framework of the AC-GCM EMAC. As a first application, we plan to use MADE3 for a reassessment of the shipping effect on the global atmospheric aerosol, because coarse mode particle interactions with condensable gases and with small particles may play an important role in that context. Therefore, we added black carbon (BC) emissions, and prescribed gaseous $\mathrm{H}_{2} \mathrm{SO}_{4}$ and $\mathrm{HNO}_{3}$ production rates in our test case, thus simulating an episode of heavy ship traffic.

We simulated $24 \mathrm{~h}$ of aerosol processing (without transport and deposition, see Sect. 2) under constant environmental conditions, with a constant $\mathrm{BC}$ emission rate and constant $\mathrm{H}_{2} \mathrm{SO}_{4}$ and $\mathrm{HNO}_{3}$ formation rates. This scenario can be regarded as an idealised representation of a stagnant air mass in a shipping corridor. For the time steps we chose typical (model-specific) values: 1800 s, i.e. $30 \mathrm{~min}$, in MADE3 and MADE, and $1 \mathrm{~s}$ in PartMC-MOSAIC. Gas phase chemistry is not considered, because we want to focus on the particulate phase here.

Environmental parameters as well as initial gas and aerosol concentrations were extracted from a previous multiyear EMAC simulation using the MADE3 predecessor MADE-in (evaluated in Aquila et al., 2011). For our test case, we picked a grid box in the Indian Ocean with $T=286 \mathrm{~K}$, $p=1.02 \times 10^{5} \mathrm{~Pa}$, and $\mathrm{RH}=0.771$. The initial aerosol state (as represented in MADE3) is shown in Fig. 2, and the initial number and species mass concentrations per size range, i.e. summed over the respective soluble, mixed, and insoluble modes, are given in Table 3. Initial gas concentrations are as follows: $\left[\mathrm{H}_{2} \mathrm{SO}_{4}\right]=3.75 \times 10^{-7} \mu \mathrm{g} \mathrm{m}^{-3},\left[\mathrm{NH}_{3}\right]=$ $0.240 \mu \mathrm{g} \mathrm{m}^{-3},\left[\mathrm{HNO}_{3}\right]=0$, and $[\mathrm{HCl}]=0$.

As MADE-in represents coarse mode particles by only one mode, we redistributed the species mass concentrations among the MADE3 coarse modes as follows:
Table 3. Initial number and species mass concentrations in the Aitken, accumulation, and coarse mode size ranges (summed over the respective soluble, mixed, and insoluble modes). Abbreviations are as follows: POM for particulate organic matter, BC for black carbon, and DU for mineral dust.

\begin{tabular}{|c|c|c|c|}
\hline & Aitken mode & Accumulation mode & Coarse mode \\
\hline \multicolumn{4}{|c|}{ Number concentrations $\left[\mathrm{m}^{-3}\right]$} \\
\hline & $7.34 \times 10^{7}$ & $3.51 \times 10^{6}$ & $3.44 \times 10^{6}$ \\
\hline \multicolumn{4}{|c|}{ Species mass concentrations $\left[\mu \mathrm{g} \mathrm{m}^{-3}\right]$} \\
\hline $\mathrm{SO}_{4}$ & $2.37 \times 10^{-4}$ & 0.0425 & 0 \\
\hline $\mathrm{NH}_{4}$ & $8.89 \times 10^{-5}$ & $2.86 \times 10^{-8}$ & 0 \\
\hline $\mathrm{NO}_{3}$ & 0 & 0.0161 & 0 \\
\hline $\mathrm{Na}$ & 0 & 0.161 & 6.51 \\
\hline $\mathrm{Cl}$ & 0 & 0.200 & 8.10 \\
\hline POM & $4.17 \times 10^{-5}$ & $9.31 \times 10^{-5}$ & 0 \\
\hline $\mathrm{BC}$ & $1.12 \times 10^{-6}$ & $7.24 \times 10^{-6}$ & 0 \\
\hline DU & 0 & $2.42 \times 10^{-6}$ & 0.00266 \\
\hline $\mathrm{H}_{2} \mathrm{O}$ & 0 & 1.21 & 44.1 \\
\hline
\end{tabular}

- sea spray: $50 \%$ to the soluble mode, $50 \%$ to the mixed mode;

- mineral dust (DU): $50 \%$ to the mixed mode, $50 \%$ to the insoluble mode;

- $\mathrm{H}_{2} \mathrm{O}$ : approximately $50 \%$ each to the soluble mode and the mixed mode and $1.6 \times 10^{-4} \%$ to the insoluble mode (in order to keep the $\mathrm{H}_{2} \mathrm{O}$ mass fraction of the latter below the $10 \%$ threshold upon initialisation).

Other species are not included in the initial coarse mode particle composition because MADE-in does not allow simulation of other components in the coarse mode. Splitting up the MADE-in sea spray tracer, we assigned $45 \%$ of the mass concentration to the MADE3 Na tracer and $55 \%$ to the MADE3 $\mathrm{Cl}$ tracer. This speciation is in accordance with the assumptions in EQSAM on sea spray composition. The redistribution of number concentration was derived from the mass concentrations in the coarse modes under the assumption that all three modes should initially have the same median diameter.

Transformation of the initial aerosol state to the MADE representation is straightforward: mass and number concentrations from the MADE-in Aitken modes were summed up and assigned to the MADE Aitken mode, and the same procedure was applied to the accumulation modes. For the coarse mode, the MADE-in output could be used without modifications.

In terms of median diameters, number concentrations, and mode widths, PartMC-MOSAIC was initialised with the same modes as MADE3, translated to a population of individual particles. However, the MADE3 Na and DU tracers had to be further speciated for use with PartMC-MOSAIC. 


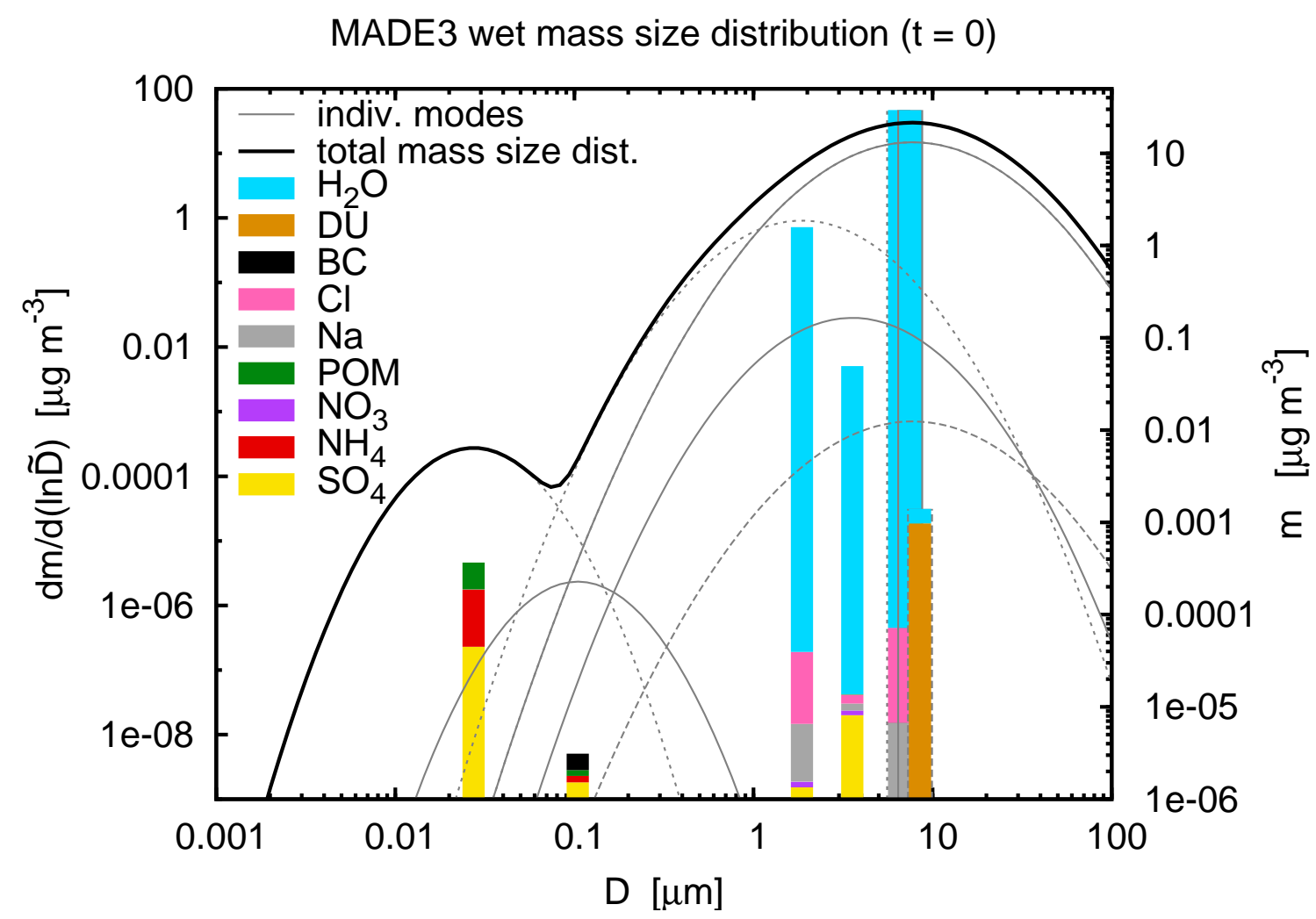

Figure 2. Initial aerosol mass size distribution and composition as represented in MADE3. The thick black line represents the mass size distribution calculated as the sum of the modes shown in grey (left vertical axis; dotted lines for soluble modes, solid lines for mixed modes, dashed lines for insoluble modes). Insoluble Aitken and accumulation mode mass concentrations are initially so small that these modes do not appear in the figure, and the curves for the soluble and mixed coarse modes lie on top of each other. The coloured bars show the contributions of the individual species $(\mathrm{POM}=$ particulate organic matter, $\mathrm{BC}=$ black carbon, $\mathrm{DU}=$ mineral dust) to the mass concentration (right vertical axis) of the respective mode (from left to right: soluble Aitken, mixed Aitken, soluble accumulation, mixed accumulation, soluble coarse, mixed coarse, insoluble coarse). Note that while the right vertical axis is logarithmic, the species fractions in the bars add up linearly to the total mass concentrations (i.e. the axis only applies to the total mass concentration in each mode, but not to the individual contributions). Note further that the three coarse mode bars were artificially spread out along the diameter axis and grey borders corresponding to the line styles of the respective modes were added for clarity.

Following again the sea spray composition assumptions in EQSAM, we assigned $69 \%$ of the MADE3 Na tracer mass concentration to the PartMC-MOSAIC Na tracer, $17 \%$ were added to the PartMC-MOSAIC $\mathrm{SO}_{4}$ tracer, $3 \%$ to the $\mathrm{Ca}$ tracer, and $11 \%$ to the other inorganic material (OIN) tracer. For the speciation of the MADE3 DU tracer into PartMCMOSAIC tracers we assumed the following mass fractions: $2 \%$ of $\mathrm{Ca}, 3 \%$ of $\mathrm{CO}_{3}$, and $95 \%$ of OIN (corresponding to $5 \% \mathrm{CaCO}_{3}$, based on data in Glaccum and Prospero, 1980; Kandler et al., 2009; Scheuvens et al., 2013).

$\mathrm{BC}$ emissions are added to the (insoluble) Aitken and accumulation modes in MADE (MADE3), and as separate particles in PartMC-MOSAIC. Our BC emission flux (see Table 4) is based on the values for ship emissions reported in the Lamarque et al. (2010) data set for the year 2000, assuming a typical marine boundary layer height of $500 \mathrm{~m}$. We chose values from a grid box off the coast of Normandy, France, and assumed a bimodal size distribution for the emitted BC particles as used in Righi et al. (2013). For the formation rates of gaseous $\mathrm{H}_{2} \mathrm{SO}_{4}$ and $\mathrm{HNO}_{3}$ (Table 4) we assumed rather high values in order to fully explore the effects of the condensation process on the microphysical calculations. These rates correspond to a direct conversion of the sulfur dioxide $\left(\mathrm{SO}_{2}\right)$ and nitrogen oxides $\left(\mathrm{NO}_{\mathrm{x}}\right)$ emitted by ships (again drawn from the Lamarque et al., 2010, data set), i.e. their choice implicitly contains the assumption of equilibrium $\mathrm{SO}_{2}$ and $\mathrm{NO}_{\mathrm{x}}$ concentrations with respect to ship emissions and formation of gaseous $\mathrm{H}_{2} \mathrm{SO}_{4}$ and $\mathrm{HNO}_{3}$.

New particle formation (NPF) is treated differently in MADE/MADE3 and PartMC-MOSAIC. Due to the large uncertainties associated with the choice of parameterisations, consideration of NPF would make the interpretation of the simulation results rather difficult. We therefore neglect the process here. In a sensitivity experiment we switched on the nucleation calculation in MADE and saw a NPF event after $\sim 3 \mathrm{~h}$ of simulated time. We added the number and mass 
Table 4. Emission and formation rates used in the test case.

\begin{tabular}{lcc}
\hline Species & $\begin{array}{c}\text { Mass conc. } \\
\text { rate of change } \\
{\left[\mathrm{kg} \mathrm{m}^{-3} \mathrm{~s}^{-1}\right]}\end{array}$ & $\begin{array}{c}\text { Number conc. } \\
\text { rate of change } \\
{\left[\mathrm{m}^{-3} \mathrm{~s}^{-1}\right]}\end{array}$ \\
\hline $\begin{array}{l}\text { Aitken mode BC } \\
\left(D_{\mathrm{g}}=70 \mathrm{~nm}, \sigma=1.45\right)\end{array}$ & $1.9 \times 10^{-16}$ & $2.6 \times 10^{2}$ \\
$\begin{array}{l}\text { Accumulation mode BC } \\
\left(D_{\mathrm{g}}=260 \mathrm{~nm}, \sigma=1.25\right)\end{array}$ & $5.0 \times 10^{-17}$ & 2.0 \\
$\mathrm{H}_{2} \mathrm{SO}_{4}$ & $1.5 \times 10^{-14}$ & - \\
$\mathrm{HNO}_{3}$ & $1.7 \times 10^{-14}$ & - \\
\hline
\end{tabular}

size distributions of these nucleated particles as simulated by MADE to the initial aerosol state for all three (sub)models. Subsequently, we switched NPF off again and re-ran the simulations. Differences in the $24 \mathrm{~h}$ number and mass size distributions between these and the original simulations were negligible for all (sub)models. Hence, we can assume that the atmospheric processing of nucleated particles is adequately treated by MADE3, i.e. growth by condensation and removal by coagulation with larger particles are properly represented.

Since some processes are treated by stochastic approaches in PartMC-MOSAIC we ran the model ten times and calculated the average of the aerosol mass and number concentrations for the ensemble of simulations. This procedure ensures that we do not discuss an "outlier" here and enables us to quantify uncertainties.

\section{Results and discussion}

\subsection{Comparison of MADE3 and MADE}

\subsubsection{Size distributions}

Number and dry mass size distributions in MADE3 and MADE at the beginning and at the end of the $24 \mathrm{~h}$ simulation are plotted vs. dry diameter in Fig. 3. Dry quantities are calculated from all aerosol components except water. Although water constitutes the largest fraction of the aerosol mass (see Fig. 4) we chose the dry representation here because the large $\mathrm{H}_{2} \mathrm{O}$ mass masks finer features in the size distribution. As aerosol water content is diagnosed from the composition of the dry aerosol anyway, no essential information is lost from the size distributions when neglecting $\mathrm{H}_{2} \mathrm{O}$ here. Deviations in the size distributions after $24 \mathrm{~h}$ in Fig. 3 are small and can be explained by the new features of MADE3 as follows.

In the fine particle size range we see a bimodal shape of the $24 \mathrm{~h}$ MADE number size distribution which is not visible in the corresponding MADE3 distribution. This difference is due to different overlaps of the initial Aitken and accumulation modes in the two submodels, which leads to a stronger convergence of median mode diameters in MADE3 than in MADE. For the initial MADE Aitken (accumulation) mode,

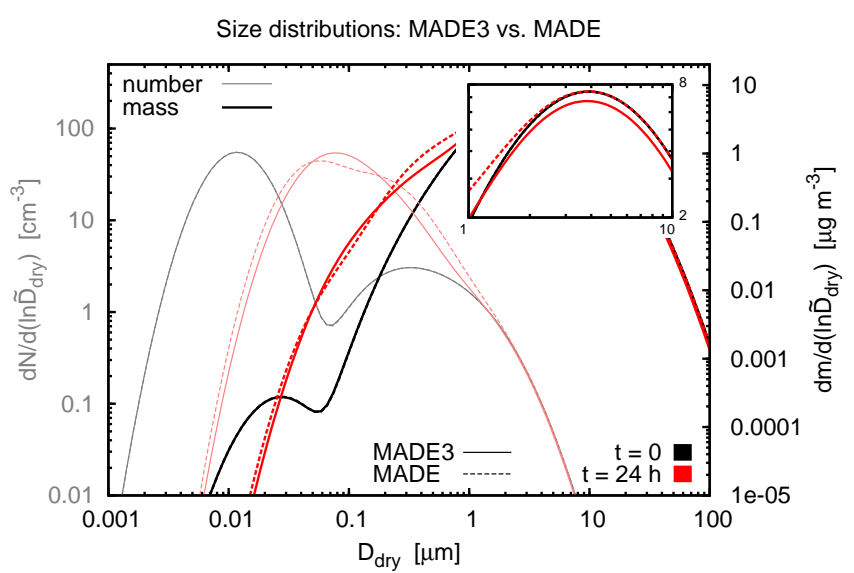

Figure 3. Initial (grey, black) and final (light red, red) size distributions in MADE3 and MADE vs. dry diameter (i.e. neglecting aerosol water). Light colours (grey, light red) are used for number distributions (left vertical axis), full colours (black, red) for dry mass distributions (right vertical axis). MADE3 output is shown as solid lines, MADE output as dashed lines. The inset magnifies the coarse mode dry mass size distributions.

we summed up species mass and number concentrations of the initial MADE3 Aitken (accumulation) modes. The associated mixing of particles in MADE leads to greater median diameters for both modes with respect to the median diameters of the soluble Aitken and accumulation modes in MADE3. These soluble modes overlap more strongly during the first hours of the simulation than the Aitken and the accumulation mode in MADE. Hence, more particles are renamed from the Aitken mode to the accumulation mode in MADE3 during that time and the accumulation mode is thus shifted towards smaller diameters. The renaming stops when the number concentration of accumulation mode particles surpasses that of the Aitken mode. This happens after about $14 \mathrm{~h}$ and after about $18 \mathrm{~h}$ of simulated time in MADE3 and MADE, respectively. Subsequently, the Aitken mode particles grow towards the accumulation modes by condensation. As this growth begins earlier in the MADE3 simulation than in the MADE simulation, the associated convergence of median diameters is more pronounced there.

In the coarse mode size range the difference in the $24 \mathrm{~h}$ mass size distributions is due to the inclusion of the $\mathrm{HCl} / \mathrm{Cl}$ equilibrium in MADE3. As we initialise the gas phase without $\mathrm{HCl}$ (see Sect. 3), equilibration requires that some of the $\mathrm{Cl}$ initially evaporates from the particles (see Fig. 4). This reduction in $\mathrm{Cl}$ is responsible for the coarse mode particles' mass loss in MADE3 with respect to MADE.

\subsubsection{Composition}

The temporal evolution of total aerosol species mass concentrations in MADE3 and MADE is plotted in Fig. 4. In both MADE3 and MADE the tracers for mineral dust 


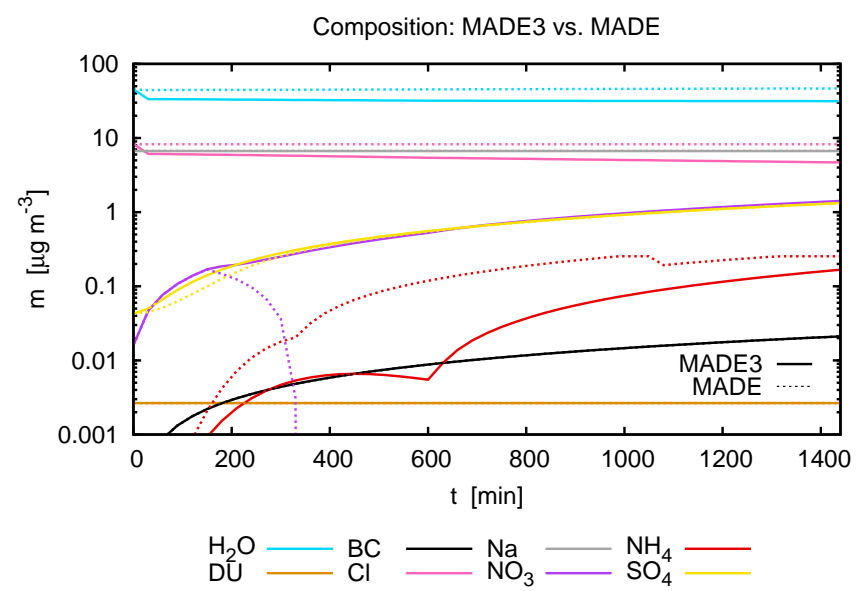

Figure 4. Temporal evolution of total aerosol species mass concentrations in MADE3 (solid lines) and MADE (dotted lines). Abbreviations are as follows: BC for black carbon and DU for mineral dust. Note that the particulate organic matter (POM) concentration is below $0.001 \mathrm{\mu g} \mathrm{m}^{-3}$ and therefore does not appear in the plot.

(DU), black carbon (BC), particulate organic matter (POM, below $0.001 \mu \mathrm{g} \mathrm{m}^{-3}$ in our test case), and $\mathrm{Na}$ (as part of the sea spray tracer in MADE) always remain in the condensed phase. Since we neglect particle mass sinks other than evaporation here, the results for these tracers are therefore identical. $\mathrm{SO}_{4}$ formation is faster in MADE3 than in MADE due to the inclusion of $\mathrm{H}_{2} \mathrm{SO}_{4}$ condensation on the coarse mode particles. The most significant differences are seen in the $\mathrm{H}_{2} \mathrm{O}, \mathrm{Cl}, \mathrm{NO}_{3}$, and $\mathrm{NH}_{4}$ evolutions, where the $\mathrm{Cl}$ deviation was already described in the previous section and the loss of $\mathrm{H}_{2} \mathrm{O}$ in MADE3 is due to the loss of $\mathrm{Cl}$.

The $\mathrm{NH}_{4}$ uptake in MADE3 in the beginning of the simulation is coupled to $\mathrm{SO}_{4}$ uptake into the soluble Aitken mode particles. This process also occurs in the soluble accumulation mode, but only after $\mathrm{NaNO}_{3}$ has been completely displaced by $\mathrm{Na}_{2} \mathrm{SO}_{4}(\sim 600 \mathrm{~min}$; note that no $\mathrm{Na}$ is present in the Aitken modes in our test case). In EQSAM sodium ions and sulfate are neutralised first. $\mathrm{NO}_{3}$ therefore evaporates from the soluble accumulation mode particles because of the condensation of $\mathrm{H}_{2} \mathrm{SO}_{4}$ and subsequent replacement of $\mathrm{NaNO}_{3}$ by $\mathrm{Na}_{2} \mathrm{SO}_{4}$. When sulfate can no longer be neutralised by $\mathrm{Na}_{2} \mathrm{SO}_{4}$ formation alone it becomes available for neutralisation by ammonium, leading to uptake of the latter into the particles. This transition is visible as the kink in the MADE3 $\mathrm{NH}_{4}$ curve $(\sim 600 \mathrm{~min})$. The same applies to the MADE Aitken and accumulation modes (see kink at $\sim 300 \mathrm{~min}$ ) but proceeds faster because coarse mode particles are not a sink for the semi-volatile gases in MADE. This missing sink is also the reason for the second kink in the MADE $\mathrm{NH}_{4}$ evolution. As all the $\mathrm{H}_{2} \mathrm{SO}_{4}$ condenses on the fine particles in MADE, they eventually enter the sulfate rich regime $(\sim 1050 \mathrm{~min})$. From this point on, sulfate ions can bind less ammonium ions because EQSAM

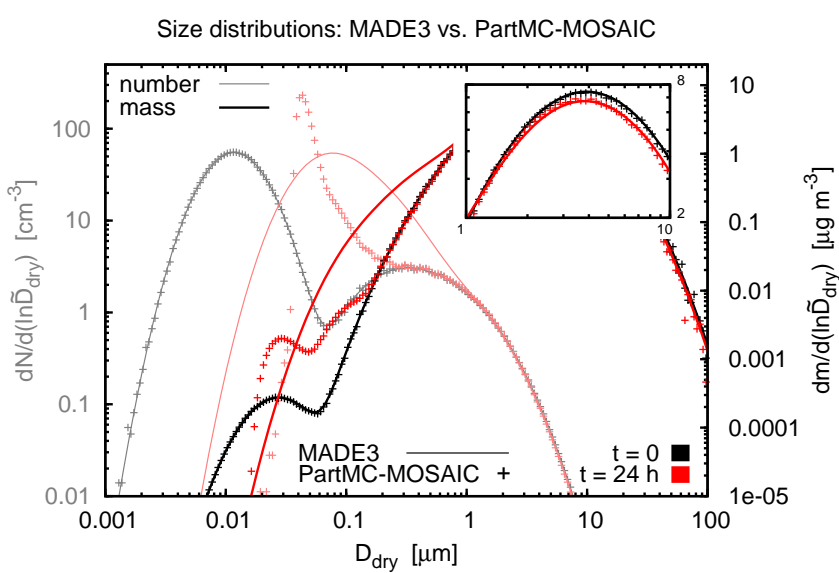

Figure 5. Initial (grey, black) and final (light red, red) size distributions in MADE3 and PartMC-MOSAIC vs. dry diameter (i.e. neglecting aerosol water). Light colours (grey, light red) are used for number distributions (left vertical axis), full colours (black, red) for dry mass distributions (right vertical axis). MADE3 output is shown as solid lines, PartMC-MOSAIC output as crosses. The inset magnifies the coarse mode dry mass size distributions.

then assumes that sulfate exists in the forms of $\left(\mathrm{NH}_{4}\right)_{2} \mathrm{SO}_{4}$, $\left(\mathrm{NH}_{4}\right)_{3} \mathrm{H}\left(\mathrm{SO}_{4}\right)_{2}$, and $\mathrm{NH}_{4} \mathrm{HSO}_{4}$ in the aerosol, whereas only $\left(\mathrm{NH}_{4}\right)_{2} \mathrm{SO}_{4}$ is considered in the sulfate neutral and sulfate poor regimes.

$\mathrm{NO}_{3}$ is taken up by the coarse mode sea spray particles in MADE3 via $\mathrm{NaNO}_{3}$ formation despite the loss from the soluble accumulation mode. MADE, however, cannot represent this process because it considers coarse mode particles as passive and only a small amount of sea spray is present in the accumulation mode size range in our simulations. Hence, we see a continued increase in aerosol $\mathrm{NO}_{3}$ content for MADE3, whereas this component is completely removed from the MADE aerosol.

\subsection{Comparison of MADE3 and PartMC-MOSAIC}

\subsubsection{Size distributions}

In analogy to Sect. 4.1.1, we first compare the size distributions calculated by MADE3 and PartMC-MOSAIC (Fig. 5). Note that the PartMC-MOSAIC results are averaged over 10 runs, but the variability is less than the size of the crosses in the figure. Only at the large-diameter and small-diameter limits of the size distributions as shown here, is the variability higher because of the very few available computational particles.

In the coarse mode size range $(\gtrsim 2 \mu \mathrm{m})$ the $24 \mathrm{~h}$ distributions of the two models agree very well. The disagreement between MADE3 and PartMC-MOSAIC in the Aitken mode size range exposes a weakness of the modal approach with fixed mode widths. The Aitken mode becomes very narrow over the course of the PartMC-MOSAIC simulation. 
However, such narrowing cannot be simulated by MADE3, as the widths of its modes remain constant. The fast growth of the smallest particles (and slower growth of the larger Aitken mode particles) by condensation, for instance, can thus not be captured as accurately in MADE3. The $24 \mathrm{~h}$ MADE3 size distribution therefore contains more particles of very small diameters than the corresponding PartMCMOSAIC distribution.

Furthermore, although total number and mass concentrations of freshly emitted BC particles are the same in both models, the size distributions upon emission are different. PartMC-MOSAIC can use the original distributions from the emissions data set as given in Table 4 (see the "shoulder" to the right of the sharp peak in the $24 \mathrm{~h}$ number size distribution in Fig. 5). In MADE3, the particles are added to the wider modes, so that their contribution to the number size distribution cannot be distinguished in Fig. 5. In addition, particle aging contributes to the less pronounced Aitken mode peak in MADE3. When the emitted BC particles acquire a coating that surpasses the mass threshold of $10 \%$, they are transferred to the mixed Aitken and accumulation modes. This leads to an increase of the median diameter of the mixed Aitken mode and to a reduction of the median diameter of the mixed accumulation mode. Hence, the two modes are no longer separately visible in the total number size distribution.

Quicker growth of soluble Aitken mode particles in terms of both mass and diameter further adds to the shift of the peak in the MADE3 number size distribution with respect to the PartMC-MOSAIC distribution. That growth is due to water uptake on these particles that is predicted by EQSAM, but not by MOSAIC. Hence, some of the particles are renamed from the soluble Aitken to the soluble accumulation mode, so that the median (dry) diameter of the soluble accumulation mode is reduced. The latter mode thus also contributes to the wide peak in the MADE3 number size distribution.

In conclusion, we see potentially significant differences between MADE3 and PartMC-MOSAIC in the size ranges of the fine particles. Such deviations had to be expected due to the simplifications and restrictions that come with the modal approach to represent particle size distributions. Despite these differences, simulation results with both models agree well in the coarse mode size range (see also the next section and the size-resolved composition plots in Appendix A). We are therefore confident that the coarse mode particle interactions that were newly introduced in MADE3 are properly represented.

\subsubsection{Composition}

The evolution of total species mass concentrations generally agrees well between MADE3 and PartMC-MOSAIC (Fig. 6). It should be noted that this agreement was achieved only after inclusion of the $\mathrm{HCl} / \mathrm{Cl}$ equilibrium in EQSAM, which leads to the decrease in $\mathrm{Cl}$ concentration and to the associated reduction of aerosol water content as described

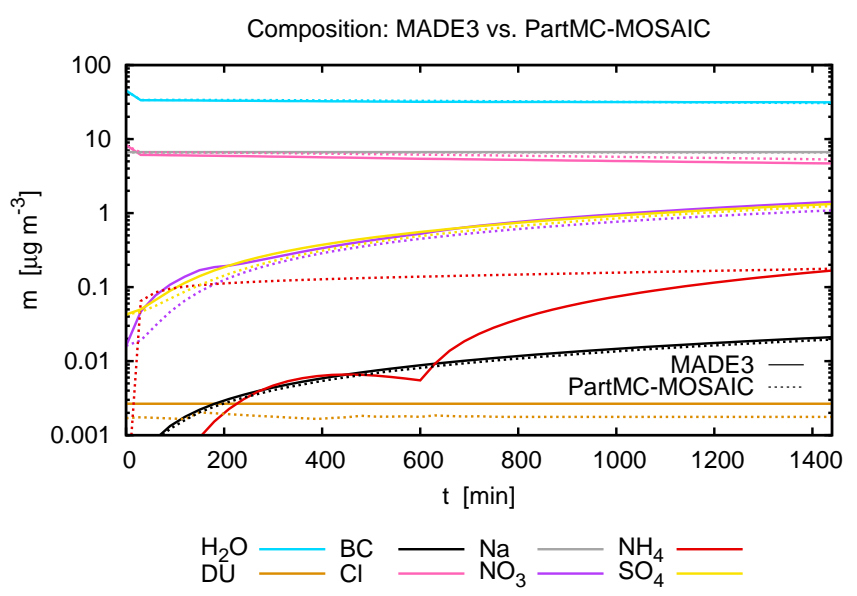

Figure 6. Temporal evolution of total aerosol species mass concentrations in MADE3 (solid lines) and PartMC-MOSAIC (dotted lines). Abbreviations are as follows: BC for black carbon and DU for mineral dust. Note that the particulate organic matter (POM) concentration is below $0.001 \mu \mathrm{g} \mathrm{m}^{-3}$ and therefore does not appear in the plot.

in Sects. 4.1.1 and 4.1.2. The difference in the mineral dust (DU) concentration is due to the very low number concentration of dust containing particles. The stochastic nature of PartMC-MOSAIC thus leads to a relatively large spread of the DU concentrations in the ten simulations (not shown). Since the MADE3 result falls within the range of simulated values this deviation does not impair the overall agreement.

$\mathrm{NO}_{3}$ is taken up more quickly in MADE3 than in PartMCMOSAIC due to the assumption that equilibrium is attained during each time step. Note that the flux limit described in Sect. 2.1.2 under "Gas-particle partitioning" is never reached in our test case. In addition, there is more $\mathrm{NO}_{3}$ partitioning to the condensed phase in MADE3 as it displaces $\mathrm{Cl}$ from the particles, leading to a slightly lower $\mathrm{Cl}$ content of the MADE3 aerosol. These differences can be explained by the different chemistry codes. While MOSAIC allows for the coexistence of $\mathrm{NaCl}$ and $\mathrm{NaNO}_{3}$ at arbitrary $\mathrm{Na}$ concentrations, $\mathrm{NaCl}$ can exist in EQSAM only when all the available nitrate has been bound to the sodium ions.

$\mathrm{SO}_{4}$ uptake is slightly slower in PartMC-MOSAIC than in MADE3. As $\mathrm{H}_{2} \mathrm{SO}_{4}$ condensation is limited by gas phase diffusion, the difference is due to the different assumptions for the accommodation coefficient: $\alpha_{\mathrm{H}_{2} \mathrm{SO}_{4}}=1$ in MADE3, $\alpha_{\mathrm{H}_{2} \mathrm{SO}_{4}}=0.1$ in PartMC-MOSAIC. Hence, the $\mathrm{H}_{2} \mathrm{SO}_{4}$ flux to the particles is greater in MADE3 than in PartMCMOSAIC (see Eq. 9). This was confirmed by a sensitivity simulation, in which we set $\alpha_{\mathrm{H}_{2} \mathrm{SO}_{4}}=0.1$ in MADE3.

The only qualitative difference between the two models in terms of composition evolution is in the $\mathrm{NH}_{4}$ concentration. It is due to the different treatments of activity coefficients by EQSAM and MOSAIC (for details, see Metzger et al., 2002; Zaveri et al., 2005b). While the activity coefficient in 
MOSAIC allows some condensed phase $\mathrm{NH}_{4} \mathrm{Cl}$ to be produced in the accumulation mode size range, EQSAM predicts that this compound will not form in our test case.

In MADE3 ammonium partitions only to the fine particles because there are not enough anions available in the coarse modes to neutralise it. In the beginning of the simulation $\mathrm{NH}_{4}$ is formed only in the smallest particles as $\left(\mathrm{NH}_{4}\right)_{2} \mathrm{SO}_{4}$. These particles eventually grow into the accumulation mode, where $\mathrm{NO}_{3}$ is taken up as $\mathrm{NaNO}_{3}$ because $\mathrm{HNO}_{3}$ is available more quickly than $\mathrm{H}_{2} \mathrm{SO}_{4}$. However, $\mathrm{SO}_{4}$ from $\mathrm{H}_{2} \mathrm{SO}_{4}$ condensation eventually displaces the $\mathrm{NO}_{3}$ in the MADE3 accumulation mode particles. When all $\mathrm{NO}_{3}$ has left these particles $(\sim 600 \mathrm{~min})$ the additionally condensing $\mathrm{SO}_{4}$ is available for $\left(\mathrm{NH}_{4}\right)_{2} \mathrm{SO}_{4}$ formation. Thus, the $\mathrm{NH}_{4}$ concentration rises more quickly thereafter.

\section{Summary and conclusions}

We have presented MADE3, a modal aerosol submodel with nine lognormal modes for use within MESSy as part of the AC-GCM EMAC. The modes represent the three classes of fully soluble, insoluble, and mixed particles in each of three size ranges, namely the Aitken, accumulation, and coarse mode size ranges. The submodel has been developed on the basis of its predecessors MADE (Ackermann et al., 1998; Lauer et al., 2005) and MADE-in (Aquila et al., 2011). It was extended by inclusion of coarse mode particle interactions with condensable trace gases and with other particles, and by inclusion of the gas-particle partitioning of chlorine. We compared the new submodel in a box model setup to its predecessor MADE and to the state-of-the-art particle-resolved aerosol box model PartMC-MOSAIC (Riemer et al., 2009; Zaveri et al., 2008), which we used as a reference here. For the comparison we designed and discussed an example test case representative of clean marine boundary layer conditions with added shipping emissions. This setup was chosen because coarse mode particle interactions potentially play an important role in such an environment.

We obtained similar results with MADE3 and MADE, but there were differences especially in the coarse mode size range. We expect to find less $\mathrm{Cl}$ and more $\mathrm{NO}_{3}$ in the aerosol particles on global average when switching from MADE to MADE3. The evaporation of some of the $\mathrm{Cl}$ to the gas phase (as $\mathrm{HCl}$ ) may entail differences in aerosol water content if the lost particulate $\mathrm{Cl}$ is not fully replaced by $\mathrm{NO}_{3}$. This, in turn, may affect the prediction of cloud condensation nuclei (CCN) concentrations and aerosol optical depth calculations. Total aerosol mass concentrations may also differ whenever sea spray particles dominate the aerosol mass concentration.
Comparing MADE3 to PartMC-MOSAIC, we found good agreement in terms of total aerosol composition evolution and coarse particle ( $\gtrsim 2 \mu \mathrm{m}$ ) size distribution predictions, despite some potentially significant differences in the size distributions of fine particles. It is important to note that the particle size distribution is one of the main factors that govern the conversion of aerosol particles to cloud droplets. In our test case, MADE3 results show a particularly large deviation from the PartMC-MOSAIC results in the size range where this activation primarily takes place. Only the 3-D model application of MADE3, i.e. the inclusion of the processes omitted here and the consideration of many different combinations of environmental parameters and aerosol population states, will allow us to check against observations whether this deviation can be generalised and whether it could lead to a systematic bias in aerosol-cloud interactions. According to the results of a comparison of a modal aerosol submodel with a sectional one within the same global chemical transport model (Mann et al., 2012), CCN concentrations may be overestimated by the modal approach in certain regions.

Nevertheless, since MADE has been extensively and successfully evaluated as part of different AC-GCMs and chemistry transport models (e.g. Lauer et al., 2005; Ochoa et al., 2012; Zhao et al., 2013; Righi et al., 2013), we are confident that MADE3 is also suitable for use with EMAC. Considering the similar results obtained with MADE3 and MADE in the box model test case that was drawn from an actual 3-D model run, we expect similar performance for MADE3 in the 3-D model as well. From the comparison with PartMCMOSAIC we conclude that improvements in the representation of coarse mode aerosol particles and total aerosol composition are likely when switching from MADE to MADE3. A corresponding evaluation within the MESSy framework by means of comparison with observational data will be the subject of a follow-up study. 


\section{Appendix A: Evolution of size-resolved aerosol composition}

In Fig. A1 we show the initial and final states of the aerosol population as simulated by MADE3 and PartMC-MOSAIC. The figure illustrates the evolution of the aerosol composition under additional consideration of the size distribution. Composition is shown in a size-binned representation to facilitate the comparison of the individual panels. The top left panel contains the same data as Fig. 2 (note that the mass fractions of mineral dust are so small that they are not visible in Fig. A1).

The lower row plots in Fig. A1, representing the aerosol state after $24 \mathrm{~h}$ of simulated time, show the same general features: higher $\mathrm{SO}_{4}$ fractions in the fine particles, predominant $\mathrm{NO}_{3}$ partitioning to large rather than small particles, and notable BC concentrations only in fine particles. Despite this agreement, one can also see that the modal approach leads to distribution of the components over wider size ranges. Since, due to their width, the modes contain particles of a broad range of sizes, this is inevitable in modal models.

The smallest particles do not take up water in PartMCMOSAIC because they are assumed to be dry initially (Zaveri et al., 2005a) and the deliquescence relative humidity of $\left(\mathrm{NH}_{4}\right)_{2} \mathrm{SO}_{4}$ is higher than the environmental relative humidity specified in our experiment (0.771). Conversely, in EQSAM, these particles do take up water due to the presence of small quantities of other components that reduce the particles' deliquescence relative humidity. 

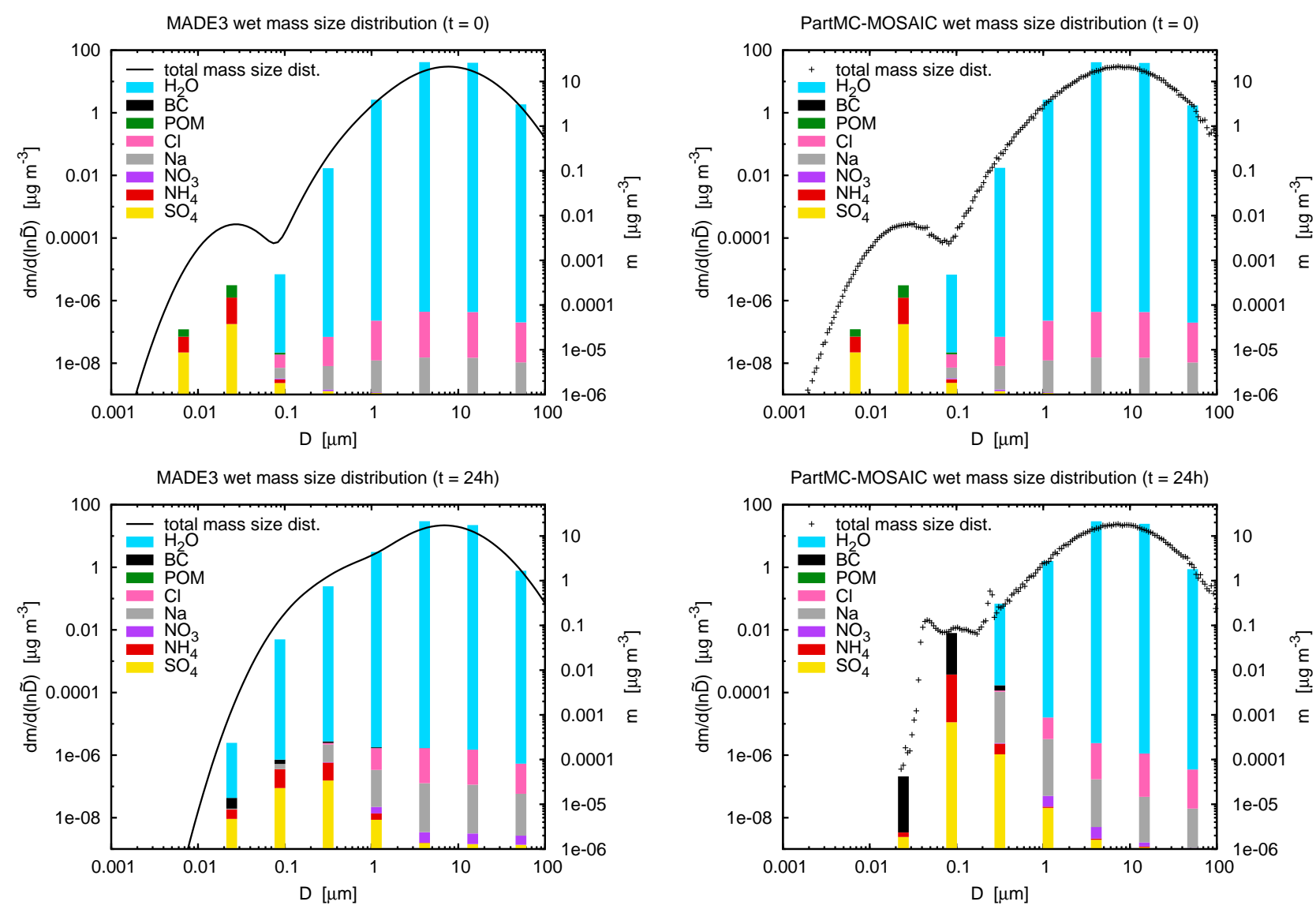

Figure A1. Aerosol mass size distributions and size-resolved composition at $t=0$ (top panels) and $t=24 \mathrm{~h}$ (bottom panels) for MADE3 (left panels) and PartMC-MOSAIC (right panels). Total mass size distributions are shown in the MADE3 panels as black lines (calculated as the sums over the modes), in the PartMC-MOSAIC panels as black crosses (left vertical axes). The coloured bars show the contributions of the individual species ( $\mathrm{POM}=$ particulate organic matter, $\mathrm{BC}=$ black carbon) to the respective mass concentrations (right vertical axes). In the PartMC-MOSAIC plots particles were binned into size sections, and the bars show the average compositions in these sections. For the MADE3 plots the binned mass concentrations were computed as the sums (across all modes) over the fractions of particles that fell within the same size sections. Note that while the right vertical axes are logarithmic, the species fractions in the bars add up linearly to the total mass concentrations (i.e. the axes only apply to the total mass concentrations in each bin, but not to the individual contributions). 


\section{Code availability}

The Modular Earth Submodel System (MESSy) is continuously further developed and applied by a consortium of institutions. The usage of MESSy, including MADE3, and access to the source code is licensed to all affiliates of institutions which are members of the MESSy Consortium. Institutions can become members of the MESSy Consortium by signing the MESSy Memorandum of Understanding. More information can be found on the MESSy Consortium Website (http://www.messy-interface.org).

Acknowledgements. We thank B. Kärcher, P. Jöckel, and R. Sausen for constructive comments that helped to improve our original manuscript. We are also grateful for the feedback provided by H. Tost (as editor), an anonymous referee, and F. Binkowski (as referee), that led to further improvement during the review process. This study was supported by the DLR transport programme. N. Riemer acknowledges funding from grant NSF-AGS 1254428. Participation of R. A. Zaveri was supported by the US Department of Energy Atmospheric System Research Program under contract DE-AC06-76RLO 1830 at Pacific Northwest National Laboratory. S. Metzger received funding from the European Research Council under the European Union's Seventh Framework Programme (FP7/2007-2013)/ERC grant agreement no. 226144. The aerosol model MADE was originally developed by the University of Cologne, Germany (RIU/EURAD project).

The service charges for this open access publication

have been covered by a Research Centre of the

Helmholtz Association.

Edited by: H. Tost

\section{References}

Ackermann, I. J., Hass, H., Memmesheimer, M., Ebel, A., Binkowski, F. S., and Shankar, U.: Modal aerosol dynamics model for Europe: development and first applications, Atmos. Environ., 32, 2981-2999, doi:10.1016/S1352-2310(98)00006-5, 1998.

Aquila, V., Hendricks, J., Lauer, A., Riemer, N., Vogel, H., Baumgardner, D., Minikin, A., Petzold, A., Schwarz, J. P., Spackman, J. R., Weinzierl, B., Righi, M., and Dall'Amico, M.: MADE-in: a new aerosol microphysics submodel for global simulation of insoluble particles and their mixing state, Geosci. Model Dev., 4, 325-355, doi:10.5194/gmd-4-325-2011, 2011.

Athanasopoulou, E., Tombrou, M., Pandis, S. N., and Russell, A. G.: The role of sea-salt emissions and heterogeneous chemistry in the air quality of polluted coastal areas, Atmos. Chem. Phys., 8, 5755-5769, doi:10.5194/acp-8-5755-2008, 2008.

Bardouki, H., Berresheim, H., Vrekoussis, M., Sciare, J., Kouvarakis, G., Oikonomou, K., Schneider, J., and Mihalopoulos, N.: Gaseous (DMS, MSA, $\mathrm{SO}_{2}, \mathrm{H}_{2} \mathrm{SO}_{4}$ and DMSO) and particulate (sulfate and methanesulfonate) sulfur species over the northeastern coast of Crete, Atmos. Chem. Phys., 3, 1871-1886, doi:10.5194/acp-3-1871-2003, 2003.

Bellouin, N., Rae, J., Jones, A., Johnson, C., Haywood, J., and Boucher, O.: Aerosol forcing in the Climate Model Intercomparison Project (CMIP5) simulations by HadGEM2-ES and the role of ammonium nitrate, J. Geophys. Res.-Atmos., 116, D20206, doi:10.1029/2011JD016074, 2011.

Bellouin, N., Quaas, J., Morcrette, J.-J., and Boucher, O.: Estimates of aerosol radiative forcing from the MACC re-analysis, Atmos. Chem. Phys., 13, 2045-2062, doi:10.5194/acp-13-20452013, 2013.

Binkowski, F. S. and Roselle, S. J.: Models-3 community multiscale air quality (CMAQ) model aerosol component 1. Model description, J. Geophys. Res.-Atmos., 108, 4183, doi:10.1029/2001JD001409, 2003.

Binkowski, F. S. and Shankar, U.: The Regional Particulate Matter Model: 1. Model description and preliminary results, J. Geophys. Res.-Atmos., 100, 26191-26209, doi:10.1029/95JD02093, 1995.

Capaldo, K. P., Pilinis, C., and Pandis, S. N.: A computationally efficient hybrid approach for dynamic gas/aerosol transfer in air quality models, Atmos. Environ., 34, 3617-3627, 2000.

Cavalli, F., Facchini, M. C., Decesari, S., Mircea, M., Emblico, L., Fuzzi, S., Ceburnis, D., Yoon, Y. J., O’Dowd, C. D., Putaud, J.-P., and Dell'Acqua, A.: Advances in characterization of size-resolved organic matter in marine aerosol over the North Atlantic, J. Geophys. Res., 109, D24215, doi:10.1029/2004JD005137, 2004.

DeVille, R., Riemer, N., and West, M.: Weighted Flow Algorithms (WFA) for stochastic particle coagulation, J. Comput. Phys., 230, 8427-8451, doi:10.1016/j.jcp.2011.07.027, 2011.

Eisele, F. L. and Tanner, D. J.: Measurement of the gas phase concentration of $\mathrm{H}_{2} \mathrm{SO}_{4}$ and methane sulfonic acid and estimates of $\mathrm{H}_{2} \mathrm{SO}_{4}$ production and loss in the atmosphere, J. Geophys. Res.Atmos., 98, 9001-9010, doi:10.1029/93JD00031, 1993.

Feng, Y. and Penner, J. E.: Global modeling of nitrate and ammonium: Interaction of aerosols and tropospheric chemistry, J. Geophys. Res.-Atmos., 112, D01304, doi:10.1029/2005JD006404, 2007.

Forster, P., Ramaswamy, V., Artaxo, P., Berntsen, T., Betts, R., Fahey, D., Haywood, J., Lean, J., Lowe, D., Myhre, G., Nganga, J., Prinn, R., Raga, G., Schulz, M., and Van Dorland, R.: Changes in atmospheric constituents and in radiative forcing, in: Climate Change 2007: The Physical Science Basis. Contribution of Working Group I to the Fourth Assessment Report of the Intergovernmental Panel on Climate Change, edited by: Solomon, S., Qin, D., Manning, M., Chen, Z., Marquis, M., Averyt, K., Tignor, M., and Miller, H., Cambridge University Press, Cambridge, UK and New York, NY, USA, 2007.

Glaccum, R. A. and Prospero, J. M.: Saharan aerosols over the tropical North Atlantic - mineralogy, Mar. Geol., 37, 295-321, doi:10.1016/0025-3227(80)90107-3, 1980.

Hara, K., Osada, K., Hayashi, M., Matsunaga, K., Shibata, T., Iwasaka, Y., and Furuya, K.: Fractionation of inorganic nitrates in winter Arctic troposphere: coarse aerosol particles containing inorganic nitrates, J. Geophys. Res.-Atmos., 104, 23671-23679, doi:10.1029/1999JD900348, 1999.

IMO: MARPOL Consolidated Edition 2011: Articles, Protocols, Annexes, Unified Interpretations of the International Convention for the Prevention of Pollution from Ships, 1973, as Modified 
by the 1978 and 1997 Protocols, IMO Publication, International Maritime Organization, 2011.

Jacobson, M. Z.: A solution to the problem of nonequilibrium acid/base gas-particle transfer at long time step, Aerosol Sci. Technol., 39, 92-103, doi:10.1080/027868290904546, 2005.

Jefferson, A., Eisele, F. L., Ziemann, P. J., Weber, R. J., Marti, J. J., and McMurry, P. H.: Measurements of the $\mathrm{H}_{2} \mathrm{SO}_{4}$ mass accommodation coefficient onto polydisperse aerosol, J. Geophys. Res.-Atmos., 102, 19021-19028, doi:10.1029/97JD01152, 1997.

Jöckel, P., Sander, R., Kerkweg, A., Tost, H., and Lelieveld, J.: Technical Note: The Modular Earth Submodel System (MESSy) - a new approach towards Earth System Modeling, Atmos. Chem. Phys., 5, 433-444, doi:10.5194/acp-5-433-2005, 2005.

Jöckel, P., Kerkweg, A., Pozzer, A., Sander, R., Tost, H., Riede, H., Baumgaertner, A., Gromov, S., and Kern, B.: Development cycle 2 of the Modular Earth Submodel System (MESSy2), Geosci. Model Dev., 3, 717-752, doi:10.5194/gmd-3-717-2010, 2010.

Johansson, L., Jalkanen, J.-P., Kalli, J., and Kukkonen, J.: The evolution of shipping emissions and the costs of regulation changes in the northern EU area, Atmos. Chem. Phys., 13, 11375-11389, doi:10.5194/acp-13-11375-2013, 2013.

Kajino, M., Inomata, Y., Sato, K., Ueda, H., Han, Z., An, J., Katata, G., Deushi, M., Maki, T., Oshima, N., Kurokawa, J., Ohara, T., Takami, A., and Hatakeyama, S.: Development of the RAQM2 aerosol chemical transport model and predictions of the Northeast Asian aerosol mass, size, chemistry, and mixing type, Atmos. Chem. Phys., 12, 11833-11856, doi:10.5194/acp12-11833-2012, 2012.

Kandler, K., Schütz, L., Deutscher, C., Ebert, M., Hofmann, H., Jäckel, S., Jaenicke, R., Knippertz, P., Lieke, K., Massling, A., Petzold, A., Schladitz, A., Weinzierl, B., Wiedensohler, A., Zorn, S., and Weinbruch, S.: Size distribution, mass concentration, chemical and mineralogical composition and derived optical parameters of the boundary layer aerosol at Tinfou, Morocco, during SAMUM 2006, Tellus B, 61, 32-50, doi:10.1111/j.16000889.2008.00385.x, 2009.

Kerminen, V.-M. and Wexler, A. S.: Enhanced formation and development of sulfate particles due to marine boundary layer circulation, J. Geophys. Res.-Atmos., 100, 23051-23062, doi:10.1029/95JD02365, 1995.

Kerminen, V. M., Pakkanen, T. A., and Hillamo, R. E.: Interactions between inorganic trace gases and supermicrometer particles at a coastal site, Atmos. Environ., 31, 2753-2765, doi:10.1016/S1352-2310(97)00092-7, 1997.

Koo, B., Gaydos, T. M., and Pandis, S. N.: Evaluation of the equilibrium, dynamic, and hybrid aerosol modeling approaches, Aerosol Sci. Technol., 37, 53-64, doi:10.1080/02786820300893, 2003.

Lamarque, J.-F., Bond, T. C., Eyring, V., Granier, C., Heil, A., Klimont, Z., Lee, D., Liousse, C., Mieville, A., Owen, B., Schultz, M. G., Shindell, D., Smith, S. J., Stehfest, E., Van Aardenne, J., Cooper, O. R., Kainuma, M., Mahowald, N., McConnell, J. R., Naik, V., Riahi, K., and van Vuuren, D. P.: Historical (1850-2000) gridded anthropogenic and biomass burning emissions of reactive gases and aerosols: methodology and application, Atmos. Chem. Phys., 10, 7017-7039, doi:10.5194/acp10-7017-2010, 2010.
Lauer, A., Hendricks, J., Ackermann, I., Schell, B., Hass, H., and Metzger, S.: Simulating aerosol microphysics with the ECHAM/MADE GCM - Part I: Model description and comparison with observations, Atmos. Chem. Phys., 5, 3251-3276, doi:10.5194/acp-5-3251-2005, 2005.

Lauer, A., Eyring, V., Hendricks, J., Jöckel, P., and Lohmann, U.: Global model simulations of the impact of ocean-going ships on aerosols, clouds, and the radiation budget, Atmos. Chem. Phys., 7, 5061-5079, doi:10.5194/acp-7-5061-2007, 2007.

Lauer, A., Eyring, V., Corbett, J. J., Wang, C., and Winebrake, J. J.: Assessment of near-future policy instruments for oceangoing shipping: impact on atmospheric aerosol burdens and the Earth's radiation budget, Environ. Sci. Technol., 43, 5592-5598, doi:10.1021/es900922h, 2009.

Mann, G. W., Carslaw, K. S., Spracklen, D. V., Ridley, D. A., Manktelow, P. T., Chipperfield, M. P., Pickering, S. J., and Johnson, C. E.: Description and evaluation of GLOMAP-mode: a modal global aerosol microphysics model for the UKCA composition-climate model, Geosci. Model Dev., 3, 519-551, doi:10.5194/gmd-3-519-2010, 2010.

Mann, G. W., Carslaw, K. S., Ridley, D. A., Spracklen, D. V., Pringle, K. J., Merikanto, J., Korhonen, H., Schwarz, J. P., Lee, L. A., Manktelow, P. T., Woodhouse, M. T., Schmidt, A., Breider, T. J., Emmerson, K. M., Reddington, C. L., Chipperfield, M. P., and Pickering, S. J.: Intercomparison of modal and sectional aerosol microphysics representations within the same 3-D global chemical transport model, Atmos. Chem. Phys., 12, 4449-4476, doi:10.5194/acp-12-4449-2012, 2012.

Meng, Z. Y. and Seinfeld, J. H.: Time scales to achieve atmospheric gas-aerosol equilibrium for volatile species, Atmos. Environ., 30, 2889-2900, doi:10.1016/1352-2310(95)00493-9, 1996.

Metzger, S., Dentener, F., Pandis, S., and Lelieveld, J.: Gas/aerosol partitioning: 1. A computationally efficient model, J. Geophys. Res.-Atmos., 107, ACH16.1-ACH16.24, doi:10.1029/2001JD001102, 2002.

Metzger, S., Mihalopoulos, N., and Lelieveld, J.: Importance of mineral cations and organics in gas-aerosol partitioning of reactive nitrogen compounds: case study based on MINOS results, Atmos. Chem. Phys., 6, 2549-2567, doi:10.5194/acp-6-25492006, 2006.

Moya, M., Pandis, S. N., and Jacobson, M. Z.: Is the size distribution of urban aerosols determined by thermodynamic equilibrium? An application to Southern California, Atmos. Environ., 36, 2349-2365, doi:10.1016/S1352-2310(01)00549-0, 2002.

Naik, V., Horowitz, L. W., Fiore, A. M., Ginoux, P., Mao, J., Aghedo, A. M., and Levy, H.: Impact of preindustrial to presentday changes in short-lived pollutant emissions on atmospheric composition and climate forcing, J. Geophys. Res.-Atmos., 118, 8086-8110, doi:10.1002/jgrd.50608, 2013.

Nair, P. and Vohra, K.: Growth of aqueous sulphuric acid droplets as a function of relative humidity, J. Aerosol Sci., 6, 265-271, doi:10.1016/0021-8502(75)90094-4, 1975.

Nolte, C. G., Bhave, P. V., Arnold, J. R., Dennis, R. L., Zhang, K. M., and Wexler, A. S.: Modeling urban and regional aerosols - application of the CMAQ-UCD Aerosol Model to Tampa, a coastal urban site, Atmos. Environ., 42, 3179-3191, doi:10.1016/j.atmosenv.2007.12.059, 2008. 
Ochoa, C., Baumgardner, D., Grutter, M., Allan, J., Fast, J., and Rappenglueck, B.: Physical and chemical properties of the regional mixed layer of Mexico's Megapolis Part II: evaluation of measured and modeled trace gases and particle size distributions, Atmos. Chem. Phys., 12, 10161-10179, doi:10.5194/acp12-10161-2012, 2012.

Olivié, D. J. L., Cariolle, D., Teyssèdre, H., Salas, D., Voldoire, A., Clark, H., Saint-Martin, D., Michou, M., Karcher, F., Balkanski, Y., Gauss, M., Dessens, O., Koffi, B., and Sausen, R.: Modeling the climate impact of road transport, maritime shipping and aviation over the period 1860-2100 with an AOGCM, Atmos. Chem. Phys., 12, 1449-1480, doi:10.5194/acp-12-1449-2012, 2012.

Peters, K., Stier, P., Quaas, J., and Graßl, H.: Aerosol indirect effects from shipping emissions: sensitivity studies with the global aerosol-climate model ECHAM-HAM, Atmos. Chem. Phys., 12, 5985-6007, doi:10.5194/acp-12-5985-2012, 2012.

Peters, K., Stier, P., Quaas, J., and Graß1, H.: Corrigendum to "Aerosol indirect effects from shipping emissions: sensitivity studies with the global aerosol-climate model ECHAM-HAM" published in Atmos. Chem. Phys., 12, 5985-6007, 2012, Atmos. Chem. Phys., 13, 6429-6430, doi:10.5194/acp-13-64292013, 2013.

Pilinis, C., Capaldo, K. P., Nenes, A., and Pandis, S. N.: MADM - a new multicomponent aerosol dynamics model, Aerosol Sci. Technol., 32, 482-502, doi:10.1080/027868200303597, 2000.

Pringle, K. J., Tost, H., Message, S., Steil, B., Giannadaki, D., Nenes, A., Fountoukis, C., Stier, P., Vignati, E., and Lelieveld, J.: Description and evaluation of GMXe: a new aerosol submodel for global simulations (v1), Geosci. Model Dev., 3, 391-412, doi:10.5194/gmd-3-391-2010, 2010a.

Pringle, K. J., Tost, H., Metzger, S., Steil, B., Giannadaki, D., Nenes, A., Fountoukis, C., Stier, P., Vignati, E., and Lelieveld, J.: Corrigendum to "Description and evaluation of GMXe: a new aerosol submodel for global simulations (v1)" published in Geosci. Model Dev., 3, 391-412, 2010, Geosci. Model Dev., 3, 413-413, doi:10.5194/gmd-3-413-2010, 2010 b.

Riemer, N., West, M., Zaveri, R. A., and Easter, R. C.: Simulating the evolution of soot mixing state with a particleresolved aerosol model, J. Geophys. Res.-Atmos., 114, D09202, doi:10.1029/2008JD011073, 2009.

Righi, M., Klinger, C., Eyring, V., Hendricks, J., Lauer, A., and Petzold, A.: Climate Impact of Biofuels in Shipping: Global Model Studies of the Aerosol Indirect Effect, Environ. Sci. Technol., 45, 3519-3525, doi:10.1021/es1036157, 2011.

Righi, M., Hendricks, J., and Sausen, R.: The global impact of the transport sectors on atmospheric aerosol: simulations for year 2000 emissions, Atmos. Chem. Phys., 13, 9939-9970, doi:10.5194/acp-13-9939-2013, 2013.

Roeckner, E., Brokopf, R., Esch, M., Giorgetta, M., Hagemann, S., Kornblueh, L., Manzini, E., Schlese, U., and Schulzweida, U.: Sensitivity of simulated climate to horizontal and vertical resolution in the ECHAM5 Atmosphere Model, J. Climate, 19, 37713791, doi:10.1175/JCLI3824.1, 2006.

Scheuvens, D., Schütz, L., Kandler, K., Ebert, M., and Weinbruch, S.: Bulk composition of Northern African dust and its source sediments - a compilation, Earth-Sci. Rev., 116, 170-194, doi:10.1016/j.earscirev.2012.08.005, 2013.
Seinfeld, J. and Pandis, S.: Atmospheric chemistry and physics: from air pollution to climate change, Wiley, Hoboken, NJ, 2nd Edn., 2006.

Tian, J., Riemer, N., West, M., Pfaffenberger, L., Schlager, H., and Petzold, A.: Modeling the evolution of aerosol particles in a ship plume using PartMC-MOSAIC, Atmos. Chem. Phys., 14, 53275347, doi:10.5194/acp-14-5327-2014, 2014.

Van Dingenen, R. and Raes, F.: Determination of the condensation accommodation coefficient of sulfuric acid on watersulfuric acid aerosol, Aerosol Sci. Technol., 15, 93-106, doi:10.1080/02786829108959516, 1991.

Vehkamäki, H., Kulmala, M., Napari, I., Lehtinen, K. E. J., Timmreck, C., Noppel, M., and Laaksonen, A.: An improved parameterization for sulfuric acid-water nucleation rates for tropospheric and stratospheric conditions, J. Geophys. Res., 107, 4622-4631, doi:10.1029/2002JD002184, 2002.

Vehkamäki, H., Kulmala, M., Napari, I., Lehtinen, K. E. J., Timmreck, C., Noppel, M., and Laaksonen, A.: Correction to "An improved parameterization for sulfuric acid/water nucleation rates for tropospheric and stratospheric conditions", J. Geophys. Res.Atmos., 118, 9330-9330, doi:10.1002/jgrd.50603, 2013.

Vignati, E., Wilson, J., and Stier, P.: M7: An efficient size-resolved aerosol microphysics module for large-scale aerosol transport models, J. Geophys. Res., 109, D22202, doi:10.1029/2003JD004485, 2004.

Wan, H., Rasch, P. J., Zhang, K., Kazil, J., and Leung, L. R.: Numerical issues associated with compensating and competing processes in climate models: an example from ECHAM-HAM, Geosci. Model Dev., 6, 861-874, doi:10.5194/gmd-6-861-2013, 2013.

Wexler, A. S. and Seinfeld, J. H.: The distribution of ammonium salts among a size and composition dispersed aerosol, Atmos. Environ. A-Gen., 24, 1231-1246, doi:10.1016/09601686(90)90088-5, 1990.

Wexler, A. S. and Seinfeld, J. H.: Analysis of aerosol ammonium nitrate: Departures from equilibrium during SCAQS, Atmos. Environ. A-Gen., 26, 579-591, doi:10.1016/0960-1686(92)90171-G, 1992.

Whitby, E. R., McMurry, P. H., Shankar, U., and Binkowski, F. S.: Modal aerosol dynamics modeling, Tech. Rep. EPA-68-01-7365, US Environmental Protection Agency, Office of Research and Development, Atmospheric Research and Exposure Assessment Laboratory, Research Triangle Park, NC, available at: http:// nepis.epa.gov/Exe/ZyPURL.cgi?Dockey=9100J9AO.txt (last access: 13 June 2012), 1991.

Yeatman, S. G., Spokes, L. J., and Jickells, T. D.: Comparisons of coarse-mode aerosol nitrate and ammonium at two polluted coastal sites, Atmos. Environ., 35, 1321-1335, doi:10.1016/S1352-2310(00)00452-0, 2001.

Zaveri, R. A., Easter, R. C., and Peters, L. K.: A computationally efficient Multicomponent Equilibrium Solver for Aerosols (MESA), J. Geophys. Res.-Atmos., 110, D24203, doi:10.1029/2004JD005618, 2005a.

Zaveri, R. A., Easter, R. C., and Wexler, A. S.: A new method for multicomponent activity coefficients of electrolytes in aqueous atmospheric aerosols, J. Geophys. Res.-Atmos., 110, D02201, doi:10.1029/2004JD004681, 2005b. 
Zaveri, R. A., Easter, R. C., Fast, J. D., and Peters, L. K.: Model for Simulating Aerosol Interactions and Chemistry (MOSAIC), J. Geophys. Res.-Atmos., 113, D13204, doi:10.1029/2007JD008782, 2008.
Zhao, C., Ruby Leung, L., Easter, R., Hand, J., and Avise, J.: Characterization of speciated aerosol direct radiative forcing over California, J. Geophys. Res.-Atmos., 118, 2372-2388, doi:10.1029/2012JD018364, 2013. 